\title{
Fuzzy sliding mode control of plate vibrations
}

\author{
Manu Sharma ${ }^{\mathrm{a}, *}$ and S.P. Singh ${ }^{\mathrm{b}}$ \\ ${ }^{a}$ University Institute of Engineering \& Technology, Panjab University, Chandigarh, India \\ ${ }^{\mathrm{b}}$ Department of Mechanical Engineering, Indian Institute of Technology, Hauz Khas, New Delhi-110016, India
}

Received 10 September 2008

Revised 16 February 2009

\begin{abstract}
In this paper, fuzzy logic is meshed with sliding mode control, in order to control vibrations of a cantilevered plate. Test plate is instrumented with a piezoelectric sensor patch and a piezoelectric actuator patch. Finite element method is used to obtain mathematical model of the test plate. A design approach of a sliding mode controller for linear systems with mismatched time-varying uncertainties is used in this paper. It is found that chattering around the sliding surface in the sliding mode control can be checked by the proposed fuzzy sliding mode control approach. With presented fuzzy sliding mode approach the actuator voltage time response has a smooth decay. This is important because an abrupt decay can excite higher modes in the structure. Fuzzy rule base consisting of nine rules, is generated from the sliding mode inequality. Experimental implementation of the control approach verify the theoretical findings. For experimental implementation, size of the problem is reduced using modal truncation technique. Modal displacements as well as velocities of first two modes are observed using real-time kalman observer. Real time implementation of fuzzy logic based control has always been a challenge because a given set of rules has to be executed in every sampling interval. Results in this paper establish feasibility of experimental implementation of presented fuzzy logic based controller for active vibration control.
\end{abstract}

\section{Nomenclature}

$\begin{array}{ll}\Delta A_{1}(t) & \text { Mismatched time varying uncertainty } \\ \Delta A_{2}(t) & \text { Matched time varying uncertainty } \\ A, B & \text { State matrices of state space model } \\ a, b & \text { Parameters used to define fuzzy sets } \\ C & \text { Vector defining sliding surface } \\ Q & \text { Volume } \\ q & \text { Applied surface charge density } \\ S & \text { Sliding surface } \\ s & \text { State vector } \\ T & \text { Transformation matrix for converting state space model into regular form } \\ T_{e} & \text { Element kinetic energy } \\ V_{e} & \text { Element potential energy } \\ W_{e e} & \text { Element electric energy } \\ W_{e} & \text { Work done by the surface force and the surface electrical charge } \\ u(t) & \text { Control input } \\ u_{m}(t) & \text { Partial control input } \\ v & \text { Voltage across the piezoelectric patch } \\ w & \text { Normal displacement variable }\end{array}$

\footnotetext{
* Corresponding author: Dr. Manu Sharma, Lecturer, University Institute of Engineering \& Technology, Panjab University, Chandigarh, India. Tel.: +91 172 2534977; E-mail: sharma_iitd@yahoo.co.in.
} 


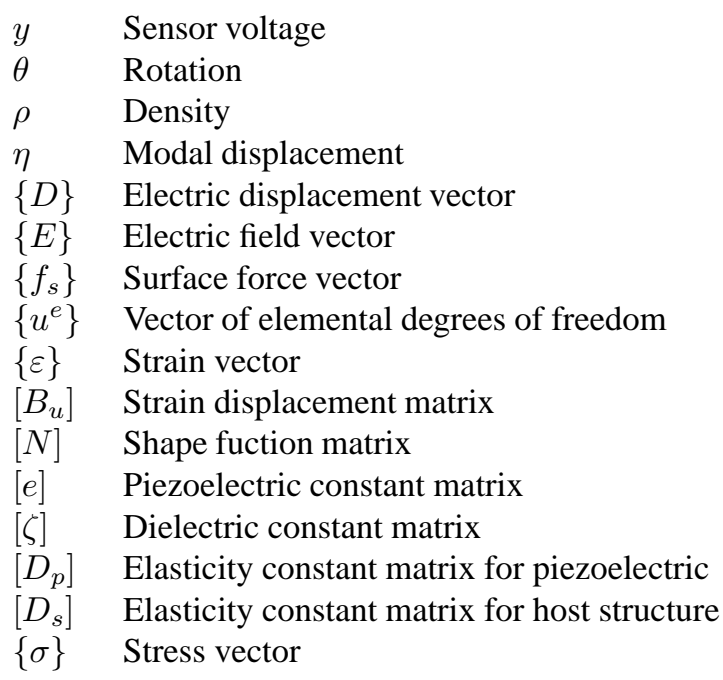

\section{Introduction}

Man has always been trying hard to control unwanted structural vibrations. Passive vibration control technique, in which no external source of energy is employed, has been used since time immemorial. Active vibration control technique, in which some external source of energy is employed, is a recent technique. An active vibration control scheme essentially requires sensor/sensors, processor and actuator/actuators. Vibration signal sensed by sensor/sensors is suitably processed by the processor and then fed back to the actuator/actuators. With the advent of fast computers, field of active vibration control has picked up. Active vibration control is now becoming a commercial proposal with the availability of economical on-board computers, smart materials and intelligent control techniques.

Active vibration control problem has been tackled using various control techniques like 'Independent modal space control' (IMSC) \& 'Modified independent modal space control' (MIMSC) [3,15], 'Linear quadratic regulator' (LQR) [2,4,21], 'Pole placement' [14], Efficient modal control [17], 'LMS algorithm' [1,13] etc. Feedback control of structures has been very well documented in books by Meirovitch [15], Inman [10] and Preumont [16]. Book of Fuller et al. [8] has admirably treated feedforward control of structures. Tokhi and Veres [19] have dealt with feedback control, feedforward control and also intelligent control approaches like neural networks, genetic algorithms etc. Present day research thrust is on designing robust, adaptive and intelligent controllers for active vibration control. Therefore, fuzzy logic, neural networks, sliding mode control etc have been of interest to researchers all over the globe. Fuzzy control is as if a human being is in the control loop, so it is very suitable in cases where plant model is not available or is rough or where plant itself keeps on changing. One of the firsts, to employ fuzzy control for the vibration suppression of structures were Tsoukkas and Vanlandingham [20]. They suggested 49 rules based on the displacement and the difference in the displacement in subsequent time, i.e. velocity. The effectiveness of the fuzzy control was demonstrated theoretically by applying it to the beam model. However, the hardware implementation of these rules reveals potential problems since 49 rules should be processed in parallel and in realtime, which implies that the controller should be fast enough to compute the output under fuzzy rules in a sampling period. Sampling rate of $5 \mathrm{kHz}$ was used in the numerical demonstration. These 49 rules proposed by Tsoukkas and Vanlandingham [20] were reduced to just 4 by Kwak and Sciulli [11], employing sliding-mode control. They performed real-time fuzzy control experiment on the cantilever beam with surface-bonded piezoceramic sensors and actuators. Pseudo-collocated sensors and actuators were realised by putting them as closely to each other as possible. Using sliding mode theory, individual switching surface for each collocated sensor and actuator was written as a function of displacement and velocity picked up by the sensor. Value of the switching surface was fed as an input to the fuzzy controller and control voltage was obtained. Tricky part in fuzzy logic control is the generation of the rule base. Generation of rule base becomes easy if sliding mode control theory is applied. In this way fuzzy control 
becomes less dependent on human logic. Ting et al. [18] employed a sliding-mode-fuzzy control strategy to design a stable controller for a quarter-car (2-dof) model of the active suspension system. The controller was organised at two levels. At the basic level, the fuzzy control rule sets and inference mechanism were constructed to generate a fuzzy control scheme. This fuzzy control scheme was based on sliding mode control theory. The fuzzy controller had two inputs viz. sliding surface and its change. At the supervisory level, a self-tuning device based on fuzzy logic was established to adjust the output gain of the fuzzy control scheme. The controller was found to perform satisfactorily in perturbed conditions also.

For a complex structure, the inevitable existences of parameter uncertainties, measurement errors, etc., make it difficult to construct an accurate model which can be used for the controller design. Under these circumstances, robust vibration control $\left(\mathrm{H}_{2} / \mathrm{H}_{\infty}, \mu\right.$ control, sliding mode control) coupled with fuzzy logic seems a promising option. Choi and Kim [7] presented a new discrete-time, fuzzy sliding-mode controller with application to vibration control of a smart structure featuring a piezofilm actuator. Fuzzy-logic was used to appropriately determine principal control parameters such as a discontinuous feedback gain of the main sliding-mode controller. The first and second flexible modes were considered as the primary modes to be controlled in the implementation. The controller was found to work well when natural frequencies of the beam were perturbed by placing a mass at the tip of the beam. Choi and Kim [6] developed a fuzzy-sliding-mode controller for robust tracking of robotic manipulators. Firstly, a sliding-mode controller was made, and then the discontinuous feedback gain of the sliding-mode controller was properly adjusted according to the commanded fuzzy rules. Value of sliding-surface and its gradient were fed as an input to the fuzzy controller. This controller had 25 rules. Li and Yam [12] have used model-based fuzzy control for robust active vibration control of a thin plate. Robustness of the controller was achieved by updating a coefficient matrix of the controller using online recursive ARMAX approach.

It is difficult to model the boundary conditions. Moreover, boundary conditions keep on changing with time. So, there is an amount of uncertainty in the mathematical model of the system. Uncertainties are also present due to parametric variations of the system which occur as a result of interaction between the system and the surrounding environment. For example, external disturbance can erode-away some mass of the test plate. This will alter effective mass, stiffness and damping of the test plate, thereby changing overall dynamic characteristics. Sliding mode control (SMC), or variable structure control, is robust to system uncertainties and external disturbances when the system trajectories belong to predetermined sliding surfaces. Drawback of SMC is that it requires instantaneous change of control input. This may cause chattering of control input and as a result excite high frequency modes. Chattering can fatigue the actuators, so it should be reduced as much as possible. To reduce chattering, a saturation function featuring a boundary layer of the sliding surface is normally used. In this paper, chattering has been attenuated by fuzzy logic. Fuzzy variables and rules are obtained from the sliding motion inequality. Simulation and experiments testify the proposed controller. For the basic sliding mode control, the formulation given by Chan et al. [5] has been adopted for a vibratory system. In the work done by Chan et al. [5], the additional flexibility offered by the controller is that the uncertainties in the plant can be mismatched i.e. they need not be expressible in terms of the control matrix.

\section{Finite element formulation}

Consider a flexible elastic plate structure, as shown in Fig. 1. Plate is instrumented with a piezoelectric sensoractuator pair, polarized in thickness direction. The top and bottom surface of each piezoelectric patch is covered by equipotential electrodes. At the device location, structure is composite in thickness direction, with two piezoelectric and one elastic layer. The plate is modeled using finite element method. Piezoelectric materials have coupled electromechanical properties.

Linear constitutive equations for piezoelectric materials relate electric displacement and stress to strain and electric field. These equations as in IEEE standard on piezoelectricity [9] are:

$$
\begin{aligned}
& D_{i}=e_{i q} \varepsilon_{q}+\zeta_{i k}^{s} E_{k} \\
& \sigma_{r}=\left(D_{p}\right)_{r q}^{E} \varepsilon_{q}-e_{k r} E_{k}
\end{aligned}
$$




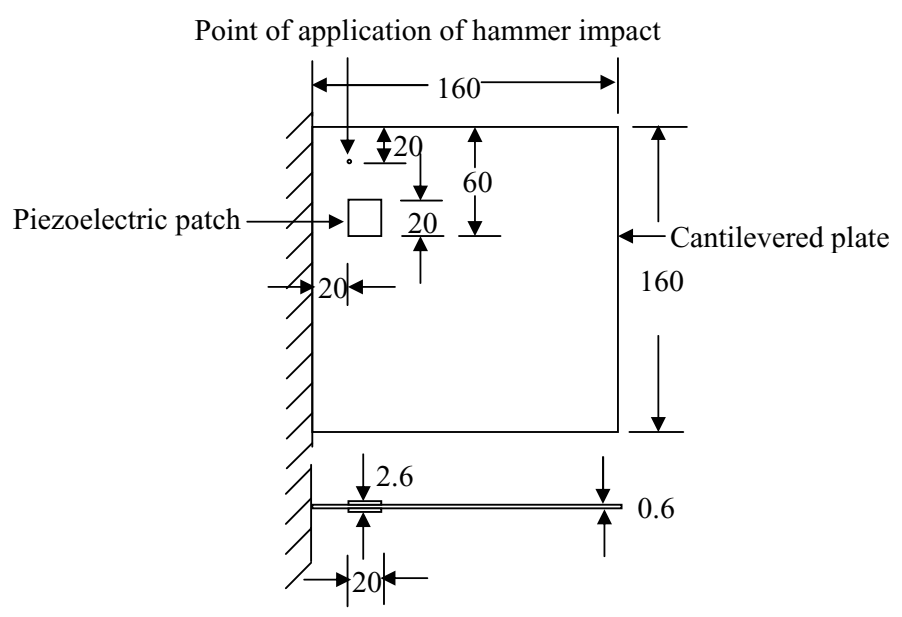

Fig. 1. Test plate instrumented with piezoelectric patches (dimensions in $\mathrm{mm}$ ).

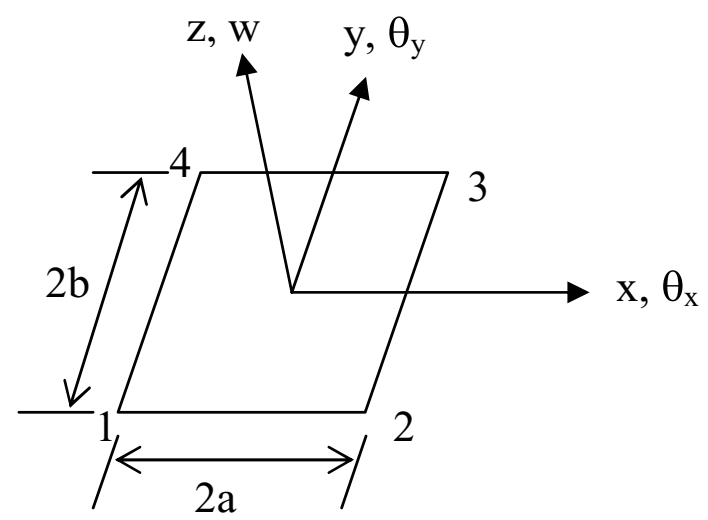

Fig. 2. Quadrilateral plate element.

Subscripts $r \& q=1,2,3,4,5,6$ and $k \& i=1,2,3$. Where $D, E, \varepsilon$ and $\sigma$ are the electric displacement, electric field, strain and stress vectors respectively. $D_{p}, e, \zeta$ are the elasticity, piezoelectric constant and dielectric constant matrices respectively. Equation (1) describes the direct piezoelectric effect and Eq. (2) describes the inverse piezoelectric effect. Equations (1) and (2) can be written in simple form as

$$
\begin{gathered}
\{D\}=[e]\{\varepsilon\}+[\zeta]\{E\} \\
\{\sigma\}=\left[D_{p}\right]\{\varepsilon\}-[e]^{T}\{E\}
\end{gathered}
$$

For elastic field in the structure alone, the constitutive equation is:

$$
\{\sigma\}=\left[D_{s}\right]\{\varepsilon\}
$$

Where $D_{s}$ is the elasticity constant matrix of the main structure.

The arbitrary quadrilateral bending element of plate is adopted in this work for finite element formulation. Figure 2 shows the element with four node points, one at each corner.

There are three degrees of freedom at each node, namely, the component of displacement normal to the plane of the plate, $w$, and the two rotations $\theta_{x}$ and $\theta_{y}$. The normal displacement variable $w$ is expressed as the function of nodal displacement variable by finite element interpolation functions as follows: 


$$
\begin{aligned}
w & =\left[N_{1} N_{2} N_{3} N_{4}\right]\left\{u^{e}\right\} \\
& =[N]\left\{u^{e}\right\}
\end{aligned}
$$

Where, $N_{1}, N_{2}, N_{3}$ and $N_{4}$ are the interpolation function and vector of elemental degrees of freedom is given by:

$$
\left\{u^{e}\right\}^{T}=\left[w_{1} \theta_{x 1} \theta_{y 1} \ldots, w_{4} \theta_{x 4} \theta_{y 4}\right]
$$

The element kinetic energy is:

$$
T_{e}=\frac{1}{2} \int_{Q_{s}} \rho_{s} \dot{w}^{2} d Q+\frac{1}{2} \int_{Q p} \rho_{p} \dot{w}^{2} d Q
$$

Subscripts $s, p$ refer to main structure, piezoelectric structure respectively. Substituting for $w$ from Eq. (6), we have

$$
T_{e}=\frac{1}{2} \rho_{S} \int_{Q s}\left\{\dot{u}^{e}\right\}^{T}[N]^{T}[N]\left\{\dot{u}^{e}\right\} d Q+\frac{1}{2} \rho_{p} \int_{Q p}\left\{\dot{u}^{e}\right\}^{T}[N]^{T}[N]\left\{\dot{u}^{e}\right\} d Q
$$

The element potential energy is:

$$
V_{e}=\frac{1}{2} \int_{Q s}\{\varepsilon\}^{T}\{\sigma\} d Q+\frac{1}{2} \int_{Q p}\{\varepsilon\}^{T}\{\sigma\} d Q
$$

Using Kirchhoff (classical) plate theory and Eq. (6), the strain variable is expressed as the function of nodal displacement variables as

$$
\{\varepsilon\}=z\left\{\begin{array}{l}
-\frac{\partial^{2} w}{\partial x^{2}} \\
-\frac{\partial^{2} w}{\partial y^{2}} \\
-2 \frac{\partial^{2} w}{\partial x \partial y}
\end{array}\right\}=z\left[B_{u}\right]\left\{u^{e}\right\}
$$

and stress variable is given by Eqs (4) and (5). Assuming linear electric field through the thickness of the piezoelectric and considering electrodes on the two opposite faces to be equipotential, the electric field vector is defined as under:

$$
\{E\}=-\left\{\begin{array}{l}
0 \\
0 \\
\frac{1}{h_{p}}
\end{array}\right\} v=-\left[B_{v}\right] v
$$

Where $v$ is voltage across the piezoelectric patch and $h_{p}$ is thickness of the piezo patch. Substituting in Eq. (10), we have

$$
V_{e}=\frac{1}{2} \int_{Q s}\{\varepsilon\}^{T}\left[D_{s}\right]\{\varepsilon\} d Q+\frac{1}{2} \int_{Q p}\{\varepsilon\}^{T}\left(\left[D_{p}\right]\{\varepsilon\}-[e]^{T}\{E\}\right) d Q
$$

with further simplification,

$$
\begin{aligned}
& V_{e}=\frac{1}{2} \int_{Q s} z^{2}\left\{u^{e}\right\}^{T}\left[B_{u}\right]^{T}\left[D_{s}\right]\left[B_{u}\right]\left\{u^{e}\right\} d Q \\
& +\frac{1}{2} \int_{Q p} z\left\{u^{e}\right\}^{T}\left[B_{u}\right]^{T}\left(z\left[D_{p}\right]\left[B_{u}\right]\left\{u^{e}\right\}+[e]^{T}\left[B_{v}\right] v\right) d Q
\end{aligned}
$$

The element electric energy is:

$$
W_{e e}=\frac{1}{2} \int_{Q p}[E]^{T}[D] d Q
$$

Substituting expressions for $[D]$ from Eq. (3) we have

$$
W_{e e}=-\frac{1}{2} \int_{Q p} v\left[B_{v}\right]^{T}([e]\{\varepsilon\}+[\xi]\{E\}) d Q
$$


Again substituting for $\{E\}$,

$$
W_{e e}=-\frac{1}{2} \int_{Q p} v\left[B_{v}\right]^{T}\left(z[e]\left[B_{v}\right]\left\{u^{e}\right\}-[\xi]\left[B_{v}\right] v\right) d Q
$$

The work done by the surface force and the applied surface electrical charge density is:

$$
W_{e}=\int_{s 1}\left\{u^{e}\right\}^{T}\left\{f_{s}^{e}\right\} d s-\int_{s 2} v q d s
$$

Where $\left\{f_{s}\right\}$ is the surface force and $q$ is applied surface electrical charge density, $s_{1}$ and $s_{2}$ are the surface areas where the surface forces and the electrical charge are applied respectively. In the present formulation, surface force is considered to be zero. Applying Hamilton's principle

$$
\int_{t_{0}}^{t_{1}} \delta L_{e} d t=\int_{t_{0}}^{t_{1}} \delta\left(T_{e}-V_{e}+W_{e e}+W_{e}\right)
$$

Making substitutions from Eqs (9), (14), (17) and (18) in Eq. (19) we have,

$$
\begin{aligned}
& \int_{t_{0}}^{t_{1}} \delta\left(\frac{1}{2} \rho_{s} \int_{Q s}\left\{\dot{u}^{e}\right\}^{T}[N]^{T}[N]\left\{\dot{u}^{e}\right\} d Q+\frac{1}{2} \rho_{p} \int_{Q p}\left\{\dot{u}^{e}\right\}^{T}[N]^{T}[N]\left\{\dot{u}^{e}\right\} d Q\right) d t \\
& \quad-\int_{t_{0}}^{t_{1}} \delta\left(\frac{1}{2} \int_{Q s} z^{2}\left\{u^{e}\right\}^{T}\left[B_{u}\right]^{T}\left[D_{s}\right]\left[B_{u}\right]\left\{u^{e}\right\} d Q\right) d t \\
& \quad-\int_{t_{0}}^{t_{1}} \delta\left(\frac{1}{2} \int_{Q p} z\left\{u^{e}\right\}^{T}\left[B_{u}\right]^{T}\left(z\left[D_{p}\right]\left[B_{u}\right]\left\{u^{e}\right\}+[e]^{T}\left[B_{v}\right] v\right) d Q\right) d t \\
& \quad-\int_{t_{0}}^{t_{1}} \delta\left(\frac{1}{2} \int_{Q p} v\left[B_{v}\right]^{T}\left(z[e]\left[B_{u}\right]\left\{u^{e}\right\}-[\xi]\left[B_{v}\right] v\right) d Q\right) d t \\
& \quad+\int_{t_{0}}^{t_{1}} \delta\left(\int_{s 1}\left\{u^{e}\right\}^{T}\left\{f_{s}^{e}\right\} d s-\int_{s 2} v q d s\right) d t=0
\end{aligned}
$$

Taking variations with respect to $u$,

$$
\begin{aligned}
& \int_{t_{0}}^{t_{1}}\left(\rho_{s} \int_{Q s}\left\{\delta \dot{u}^{e}\right\}^{T}[N]^{T}[N]\left\{\dot{u}^{e}\right\} d Q+\rho_{p} \int_{Q p}\left\{\delta \dot{u}^{e}\right\}^{T}[N]^{T}[N]\left\{\dot{u}^{e}\right\} d Q\right. \\
& \quad-\int_{Q s} z^{2}\left\{\delta u^{e}\right\}^{T}\left[B_{u}\right]^{T}\left[D_{s}\right]\left[B_{u}\right]\left\{u^{e}\right\} d Q \\
& \quad-\int_{Q p} z^{2}\left\{\delta u^{e}\right\}^{T}\left[B_{u}\right]^{T}\left[D_{p}\right]\left[B_{u}\right]\left\{u^{e}\right\} d Q-\frac{1}{2} \int_{Q p} z\left\{\delta u^{e}\right\}\left[B_{u}\right]^{T}[e]^{T}\left[B_{v}\right] v d Q \\
& \left.\quad-\frac{1}{2} \int_{Q p} v\left[B_{v}\right]^{T} z[e]\left[B_{u}\right]\left[\delta u^{e}\right] d Q+\int_{s 1}\left\{\delta u^{e}\right\}^{T}\left\{f_{s}\right\} d s\right) d t=0
\end{aligned}
$$

The use of integration by parts for the first two terms gives:

$$
\begin{aligned}
& \int_{t_{0}}^{t_{1}}\left(-\rho_{p} \int_{Q p}\left\{\delta u^{e}\right\}^{T}[N]^{T}[N]\left\{\ddot{u}^{e}\right\} d Q-\rho_{s} \int_{Q s}\left\{\delta u^{e}\right\}^{T}[N]^{T}[N]\left\{\ddot{u}^{e}\right\} d Q\right. \\
& \quad-\int_{Q s} z^{2}\left\{\delta u^{e}\right\}^{T}\left[B_{u}\right]^{T}\left[D_{s}\right]\left[B_{u}\right]\left\{u^{e}\right\} d Q \\
& \quad-\int_{Q p} z^{2}\left\{\delta u^{e}\right\}^{T}\left[B_{u}\right]^{T}\left[D_{p}\right]\left[B_{u}\right]\left\{u^{e}\right\} d Q-\frac{1}{2} \int_{Q p} z\left\{\delta u^{e}\right\}^{T}\left[B_{u}\right]^{T}[e]^{T}\left[B_{v}\right] v d Q \\
& \left.\quad \frac{1}{2} \int_{Q p} v\left[B_{v}\right]^{T} z[e]\left[B_{u}\right]\left\{\delta u^{e}\right\} d Q+\int_{s 1}\left\{\delta u^{e}\right\}^{T}[N]^{T}\left\{f_{s}\right\} d s\right) d t=0
\end{aligned}
$$

The common variation term is taken outside to provide 


$$
\begin{aligned}
& \left\{\delta u^{e}\right\}^{T} \int_{t_{0}}^{t_{1}}\left(-\rho_{p} \int_{Q p}[N]^{T}[N]\left\{\ddot{u}^{e}\right\} d Q-\rho_{s} \int_{Q s}[N]^{T}[N]\left\{\ddot{u}^{e}\right\} d Q\right. \\
& \quad-\int_{Q s} z^{2}\left[B_{u}\right]^{T}\left[D_{s}\right]\left[B_{u}\right]\left\{u^{e}\right\} d Q-\int_{Q p} z^{2}\left[B_{u}\right]^{T}\left[D_{p}\right]\left[B_{u}\right]\left\{u^{e}\right\} d Q \\
& \left.-\frac{1}{2} \int_{Q p} z\left[B_{u}\right]^{T}[e]^{T}\left[B_{v}\right] v d Q-\frac{1}{2} \int_{Q p} z\left[B_{u}\right]^{T}[e]^{T}\left[B_{v}\right] v d Q+\int_{s 1}\left\{f_{s}\right\} d s\right) d t=0
\end{aligned}
$$

To satisfy the above expression for arbitrary $\left\{\delta u^{e}\right\}^{T}$, the term in bracket should vanish. It provides the equation of motion for an element as under:

$$
\left(\left[m_{p}\right]+\left[m_{s}\right]\right)\left\{\ddot{u}^{e}\right\}+\left(\left[k_{u u s}\right]+\left[k_{u u p}\right]\right)\left\{u^{e}\right\}+\left[k_{u v}\right] v=\left\{F_{s}^{e}\right\}
$$

Where various matrices are of the form:

$$
\begin{aligned}
& {\left[m_{p}\right]=\rho_{p} \int_{Q p}[N]^{T}[N] d Q} \\
& {\left[m_{s}\right]=\rho_{s} \int_{Q s}[N]^{T}[N] d Q} \\
& {\left[k_{u u s}\right]=\int_{Q s} z^{2}\left[B_{u}\right]^{T}\left[D_{s}\right]\left[B_{u}\right] d Q} \\
& {\left[k_{u u p}\right]=\int_{Q p} z^{2}\left[B_{u}\right]^{T}\left[D_{p}\right]\left[B_{u}\right] d Q} \\
& {\left[k_{u v}\right]=\int_{Q p} z\left[B_{u}\right]^{T}[e]^{T}\left[B_{v}\right] d Q}
\end{aligned}
$$

Now, considering Eq. (20) and taking variations with respect to voltage,

$$
\begin{aligned}
& \int_{t_{0}}^{t_{1}}\left(-\frac{1}{2} \int_{Q p} z \delta v\left[B_{v}\right]^{T}[e]\left[B_{u}\right]\left\{u^{e}\right\} d Q-\frac{1}{2} \int_{Q p} \delta v\left[B_{v}\right]^{T}[e] z\left[B_{u}\right]\left\{u^{e}\right\} d Q\right. \\
& \left.\quad+\int_{Q p} \delta v\left[B_{v}\right]^{T}[\xi]\left[B_{v}\right] v d Q+\int_{s 2} \delta v q d s\right) d t=0
\end{aligned}
$$

The common variation term is taken outside to provide,

$$
\begin{aligned}
& \delta v \int_{t_{0}}^{t_{1}}\left(-\frac{1}{2} \int_{Q p} z\left[B_{v}\right]^{T}[e]\left[B_{u}\right]\left\{u^{e}\right\} d Q-\frac{1}{2} \int_{Q p}\left[B_{v}\right]^{T}[e] z\left[B_{u}\right]\left\{u^{e}\right\} d Q\right. \\
& \left.\quad+\int_{Q p}\left[B_{v}\right]^{T}[\xi]\left[B_{v}\right] v d Q+\int_{s 2} q d s\right) d t=0
\end{aligned}
$$

To satisfy the above expression for arbitrary $\delta v$, the term in bracket should vanish.

$$
\begin{aligned}
& -\frac{1}{2} \int_{Q p} z\left[B_{v}\right]^{T}[e]\left[B_{u}\right]\left\{u^{e}\right\} d Q-\frac{1}{2} \int_{Q p}\left[B_{v}\right]^{T}[e] z\left[B_{u}\right]\left\{u^{e}\right\} d Q \\
& \quad+\int_{Q p}\left[B_{v}\right]^{T}[\xi]\left[B_{v}\right] v d Q+\int_{s 2} q d s=0
\end{aligned}
$$

or

$$
-\left[k_{v u}\right]\left\{u^{e}\right\}+\left[k_{v v}\right] v+\bar{q}=0
$$

where, 


$$
\begin{aligned}
& {\left[k_{v u}\right]=\int_{Q p} z\left[B_{v}\right]^{T}[e]\left[B_{u}\right]\left\{u^{e}\right\} d Q} \\
& {\left[k_{v v}\right]=\int_{Q p}\left[B_{v}\right]^{T}[\xi]\left[B_{v}\right] v d Q} \\
& \bar{q}=\int_{s 2} q d s
\end{aligned}
$$

Substituting for $v$ from Eq. (33) in Eq. (24) we have equation of motion of an element as,

$$
\left(\left[m_{p}\right]+\left[m_{s}\right]\right)\left\{\ddot{u}^{e}\right\}+\left(\left[k_{u u s}\right]+\left[k_{u u p}\right]\right)\left\{u^{e}\right\}+\left[k_{u v}\right]\left[k_{v v}\right]^{-1}\left(-\bar{q}+\left[k_{v u}\right]\left\{u^{e}\right\}\right)=0
$$

No charge is applied on the surface of the sensor, so sensor equation can be derived from Eq. (33) as follows:

$$
\left[k_{v u}\right]\left\{u^{e}\right\}-\left[k_{v v}\right] v=0
$$

or,

$$
v=\left[k_{v v}\right]^{-1}\left[k_{v u}\right]\left\{u^{e}\right\}
$$

In finite element analysis, the solid or structure is considered as an assemblage of 'finite elements' connected at the nodes. After computing the stiffness matrix, mass matrix and nodal load vector of the elements based on the theory discussed in this section, the overall equation of equilibrium is formed by assembling these matrices using the connectivity information relating the degrees of freedom of the element and the corresponding global degrees of freedom. The problems in solid or structural mechanics require sufficient kinematic boundary conditions to be specified so that the body or the structure does not experience any rigid body motion and is in equilibrium with the loads. In the present problem boundary conditions for the plate are realized numerically by constraining all the degrees of freedom along the entire length of the fixed edge of the plate. This can be done by deleting rows corresponding to degrees of freedom on the fixed edge, from the load vector. Corresponding rows and columns in mass and stiffness matrices are also deleted. This results in mass matrix, stiffness matrix and load vector of the cantilevered plate. Now some control approach can be adopted and Newmark method can be used to solve the system of simultaneous equations.

\section{Fuzzy logic based sliding mode control}

The motion of the sliding mode is asymptotically stable, if (please see Eqs (A22) and (A26) Appendix. 'A' denotes Appendix).

$$
S^{T} \dot{S} \leqslant S^{T}\left(C_{2} B_{2} \zeta(t) z(t)-C_{2} B_{2} u_{m}(t)-k_{1} \operatorname{sgn}(S)-k_{2} S\right)<0
$$

Chan et al. [5] proposed solution given in Eq. (A23). This solution is associated with chattering problem. To attenuate chattering problem, in this work fuzzy sliding mode control is proposed. Inputs to the fuzzy sliding mode control are sliding surface and sliding surface velocity. Output of the fuzzy controller is the partial control input $u_{m}(t)$. Sliding surface and sliding surface velocity are fuzzified into fuzzy sets $N, Z$ and $P$ as shown in Fig. 3. Mamdani's min-operation fuzzy implication is employed for inference and defuzzification is done by 'center of gravity' method. 


\subsection{Rule base generation}

Sliding mode inequality is reproduced below as

$$
\begin{aligned}
S^{T} \dot{S} & \leqslant S^{T}\left(C_{2} B_{2} \zeta(t) z(t)-C_{2} B_{2} u_{m}(t)-k_{1} \operatorname{sgn}(S)-k_{2} S\right) \\
& <0
\end{aligned}
$$

If $\left|C_{2} B_{2}\right|>0$, then following rules can be generated

Rule 1 If $S$ is $P$ and $\dot{S}$ is $P$ then $u_{m}(t)$ is $P$

Justification: If $S$ is $P$ and $\dot{S}$ is $P$ then $S^{T} \dot{S}$ is positive. This implies that $u_{m}(t)$ should be $P$ in order to decrease $S^{T} \dot{S}$ (see inequality (40)).

Rule 2 If $S$ is $P$ and $\dot{S}$ is $N$ then $u_{m}(t)$ is $Z$

Justification: If $S$ is $P$ and $\dot{S}$ is $N$ then $S^{T} \dot{S}$ is negative. This implies that $u_{m}(t)$ should be $Z$ as there is no need to apply any control effort.

Rule 3 If $S$ is $P$ and $\dot{S}$ is $Z$ then $u_{m}(t)$ is $P$

Justification: If $S$ is $P$ and $\dot{S}$ is $Z$ then $S^{T} \dot{S}$ is positive. This implies that $u_{m}(t)$ should be $P$ in order to decrease $S^{T} \dot{S}$

Rule 4 If $S$ is $N$ and $\dot{S}$ is $N$ then $u_{m}(t)$ is $N$

Justification: If $S$ is $N$ and $\dot{S}$ is $N$ then $S^{T} \dot{S}$ is positive. This implies that $u_{m}(t)$ should be $N$ in order to decrease $S^{T} \dot{S}$.

Rule 5 If $S$ is $N$ and $\dot{S}$ is $Z$ then $u_{m}(t)$ is $Z$

Justification: If $S$ is $N$ and $\dot{S}$ is $Z$ then $S^{T} \dot{S}$ is negative. This implies that $u_{m}(t)$ should be $Z$ as $S^{T} \dot{S}$ is already negative and there is no need to apply any control effort.

Rule 6 If $S$ is $N$ and $\dot{S}$ is $P$ then $u_{m}(t)$ is $Z$

Justification: If $S$ is $N$ and $\dot{S}$ is $P$ then $S^{T} \dot{S}$ is negative. This implies that $u_{m}(t)$ should be $Z$ as there is no need to apply any control effort.

Rule 7 If $S$ is $Z$ and $\dot{S}$ is $Z$ then $u_{m}(t)$ is $Z$

Justification: If $S$ is $Z$ and $\dot{S}$ is $Z$ then $S^{T} \dot{S}$ is very small and by intuition it can be reasoned that there is no need to apply any control effort.

Rule 8 If $S$ is $Z$ and $\dot{S}$ is $P$ then $u_{m}(t)$ is $P$

Justification: If $S$ is $Z$ and $\dot{S}$ is $P$ then $S^{T} \dot{S}$ is positive. This implies that $u_{m}(t)$ should be $P$ in order to decrease $S^{T} \dot{S}$.

Rule 9 If $S$ is $Z$ and $\dot{S}$ is $N$ then $u_{m}(t)$ is $Z$

Justification: If $S$ is $Z$ and $\dot{S}$ is $N$ then $S^{T} \dot{S}$ is negative. This implies that $u_{m}(t)$ should be $Z$ as there is no need to apply any control effort ( $S^{T} \dot{S}$ is already negative).

Rule base of the controller used, is tabulated in Table 1. 
Table 1

Rule base of fuzzy sliding mode controller

\begin{tabular}{lclll}
\hline Partial input & Control & \multicolumn{3}{l}{ Sliding surface displacement } \\
\cline { 2 - 5 } & $\searrow$ & $\mathrm{P}$ & $\mathrm{N}$ & $\mathrm{Z}$ \\
\hline Sliding surface velocity & $\mathrm{P}$ & $\mathrm{P}$ & $\mathrm{Z}$ & $\mathrm{P}$ \\
& $\mathrm{N}$ & $\mathrm{Z}$ & $\mathrm{N}$ & $\mathrm{Z}$ \\
& $\mathrm{Z}$ & $\mathrm{P}$ & $\mathrm{Z}$ & $\mathrm{Z}$ \\
\hline
\end{tabular}

Table 2

Physical and geometrical specifications of the plate and piezoelectric patch

\begin{tabular}{lcccccccc}
\hline & $\begin{array}{c}\text { Length } \\
(\mathrm{mm})\end{array}$ & $\begin{array}{c}\text { Width } \\
(\mathrm{mm})\end{array}$ & $\begin{array}{c}\text { Thickness } \\
(\mathrm{mm})\end{array}$ & $\begin{array}{c}\mathrm{d}_{31} \\
\mathrm{~m} / \mathrm{volt}\end{array}$ & $\begin{array}{c}\mathrm{d}_{32} \\
\mathrm{~m} / \text { volt }\end{array}$ & $\begin{array}{c}\text { Density } \\
\left(\mathrm{Kg} / \mathrm{m}^{3}\right)\end{array}$ & $\begin{array}{c}\text { Young's } \\
\text { modulus } \\
\left(\mathrm{N} / \mathrm{m}^{2}\right)\end{array}$ & $\begin{array}{c}\text { Relative } \\
\text { dielectric } \\
\text { constant }\end{array}$ \\
\hline Piezo-electric & 20 & 20 & 1 & $275 \mathrm{E}-12$ & $275 \mathrm{E}-12$ & 7500 & $5 \mathrm{E} 10$ & 1600 \\
Plate & 160 & 160 & 0.6 & - & - & 7800 & $2.07 \mathrm{E} 11$ & - \\
\hline
\end{tabular}

\section{Use of boundary layer to check chattering}

One of the assumptions in the design of the SMC is that the control can be switched from one value to another infinitely fast. In practical systems this leads to chattering problem, which is a characteristic of SMC. Use of Eq. (A23) for partial control effort often causes chattering in practice. One solution is to introduce a boundary layer around the switch surface. Partial control effort is then defined in the following manner:

$$
u_{m}(t)=\frac{S}{\phi} \quad \text { if } \quad|S|<\phi
$$

else,

$$
u_{m}(t)=-\frac{B_{2}^{T} C_{2}^{T} S}{\left\|B_{2}^{T} C_{2}^{T} S\right\|} \rho
$$

where constant $\phi$ defines the thickness of the boundary layer. As a result, the system will be driven to the boundary layer, but the trajectory can not be forced to follow the line $S=0$. Chattering is avoided, since a continuous control is used within a boundary layer.

\section{Numerical simulations}

Numerical simulations are performed on the test plate shown in Fig. 1. Plate is instrumented with a collocated sensor-actuator pair. Geometrical and physical characteristics of the plate are given in Table 2.

Vector $s$ is defined in Eq. (A3) and it comprises of modal displacements and modal velocities of the plate. Designer can propose a sliding surface depending upon amount by which different modes need to be controlled. Based upon physical understanding of the problem, sliding surface of the following form is proposed

$$
S=\left[\begin{array}{llll}
10 & 1 & 800 & 10
\end{array}\right] s
$$

This way weights of $10,1,800$ and 10 have been attached to $\eta_{1}, \eta_{2}, \dot{\eta}_{1}$ and $\dot{\eta}_{2}$ respectively. It may be noticed that higher weights have been given to first modal quantities. Using Eq. (A5) in Eq. (43), we have

$$
S=\left[\begin{array}{llll}
10 & 1 & 800 & 10
\end{array}\right] T^{-1} z(t)
$$

Comparing Eq. (44) with Eq. (A12),

$$
C=\left[\begin{array}{llll}
10 & 1 & 800 & 10
\end{array}\right] T^{-1}
$$

transformation matrix $T$ and vector $B_{2}$, for the present problem are found to be respectively, 


$$
T=\left[\begin{array}{cccc}
0 & 1 & 0 & 0 \\
-0.8 & 0 & 0.3 & 0.5 \\
0.6 & 0 & 0.5 & 0.7 \\
0 & 0 & -0.8 & 0.6
\end{array}\right]
$$

$$
B_{2}=-3.1028 \mathrm{e}-004
$$

Substituting in Eq. (45),

$$
C=\left[\begin{array}{llll}
1.0 & 276.6 & 393.9 & -639.2
\end{array}\right]
$$

Vector $E$ as in Eq. (A10) is taken as,

$$
E=C \times 0.001
$$

It can be seen that this satisfies sliding coefficient matching condition given in Eq. (A28) as,

$$
\operatorname{rank}\left[C^{T}\right]=1=\operatorname{rank}\left[C^{T} \mid E^{T}\right]
$$

This satifies condition 1 of Section 4 of Appendix and from Eq. (A13), we have

$$
\begin{aligned}
& C_{1}=\left[\begin{array}{lll}
1.0 & 276.6 & 393.9
\end{array}\right] \\
& C_{2}=-639.2
\end{aligned}
$$

Condition 2 of Section 4 of Appendix is also satisfied since $C_{2} B_{2}=0.1983$, is invertible. For the present problem matrices $A_{11}$ and $A_{12}$ are found to be,

$$
\begin{aligned}
& A_{11}=\left[\begin{array}{crr}
0 & 0.0000 & 0.0001 \\
-4.9384 & 0.4985 & -0.3658 \\
-6.7325 & 0.6797 & -0.4987
\end{array}\right] \times 10^{4} \\
& A_{12}=\left[\begin{array}{r}
0.5915 \\
0.6502 \\
-0.4769
\end{array}\right]
\end{aligned}
$$

Now, consider matrix defined by,

$$
\bar{M}=A_{12}-A_{12} C_{2}^{-1} C_{1}=\left[\begin{array}{rrr}
0.0000 & 0.0001 & 0.0001 \\
-4.9384 & 0.4986 & -0.3658 \\
-6.7325 & 0.6797 & -0.4987
\end{array}\right] \times 10^{4}
$$

Eigen values of $\bar{M}$ are,

$$
\bar{\lambda}=\left\{\begin{array}{l}
-0.0053+3.2302 i \\
-0.0053-3.2302 i \\
-0.0001
\end{array}\right\} \times 10^{2}
$$

which are all negative. This satisfies condition 3 of Section 4. Since all the three conditions of Section 4 of Appendix are satisfied, so choice of sliding surface, as in Eq. (43) is alright.

Various control schemes used in this paper are depicted in block-diagram in Fig. 4. Plate is disturbed by displacing vertically the free edge (edge opposite to the cantilevered edge) by $2 \mathrm{~mm}$. Figure 5(a) shows the uncontrolled response of the sensor piezoelectric patch. Figure 5(b) and (d) presents time response of first and second modal displacement respectively. Since it is an uncontrolled case, actuator voltages are zero as in Fig. 5(c).

Plate is controlled by sliding mode control in Fig. 6. Sliding surface vector is selected such that conditions mentioned in Section 4 of Appendix are satisfied. With $k_{1}=0, k_{2}=1$ and $\rho=70$, plate is controlled by SMC. From Fig. 6(a) it is found that plate response gets attenuated in about 2 seconds and from Fig. 6(c) it is found that as soon as plate response dies down, chattering of control effort sets in. It is a wasteful expenditure of energy, it fatigues the actuator and has potential to excite higher modes of vibration. It is apparent from Fig. 6(d) that second mode 
Table 3

Parameters of the fuzzy controller

\begin{tabular}{cccc}
\hline Parameter & Sliding surface & Sliding surface velocity & Partial control input \\
\hline$a$ & 15 & 2000 & 10 \\
$b$ & 37.5 & 5000 & 180 \\
\hline
\end{tabular}

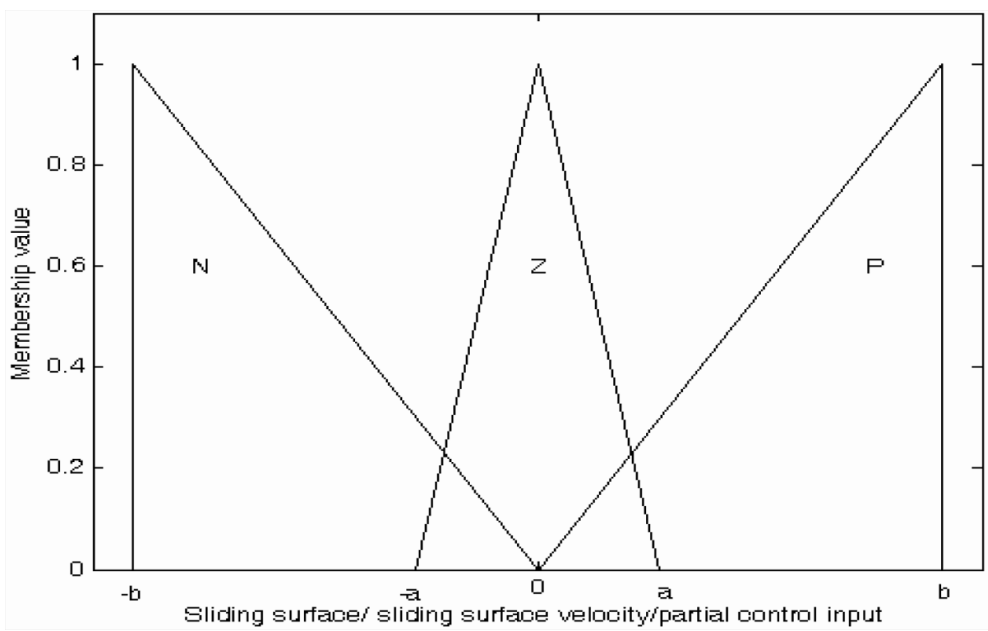

Fig. 3. Fuzzy sets for sliding surface/ sliding surface velocity/partial control input.

has been excited due to this chattering problem. Next a boundary layer is introduced while evaluating partial control input $u_{m}(t)$, as in Eqs (41) and (42). In Fig. 7, plate is controlled with $u_{m}(t)$ evaluated according to Eqs (41) and (42). Note that this modification has checked the chattering problem. Next fuzzy logic based sliding mode control is used to control the plate. Parameters $a$ and $b$ (see Fig. 3) for sliding surface, sliding surface velocity and partial control input $u_{m}(t)$ are tabulated in Table 3. Note that in Fig. 8(c) there is no chattering problem at all.

Unlike SMC without boundary layer, actuator voltage decay is very smooth in Fig. 8(c). Voltage decay does not tend to excite second mode in this case.

\section{Experimental results}

Figure 9(a) shows photograph of the test plate and Fig. 9(b) shows schematic diagram of the experimental set-up. For initiation of vibrations, the plate is given vertical displacement of $2 \mathrm{~mm}$ to entire free edge (edge opposite to the cantilevered edge) of the plate. Vibrations are sensed by a 'piezoelectric sensor', amplified by a 'charge amplifier' and then fed to 'fuzzy logic controller'. For developing the experimental controller, the control program is written using Labview Real Time and implemented via PXI controller. In the controller, the program gets downloaded and is then executed in real time operating system without any interference from the host computer. Output of controller is amplified by 'voltage amplifier' and then applied on 'piezoelectric actuator'. Dotted curve in Fig. 12 shows uncontrolled response of the plate. In Fig. 10, plate is controlled by SMC with partial control input vector $u_{m}(t)$ defined by Eq. (A23). Note that chattering problem is visible in Fig. 11 even before plate is disturbed. Chattering starts setting in as plate response starts to die down. In Fig. 12, plate is controlled by SMC with partial control $u_{m}(t)$ defined by Eqs (41) and (42). Now chattering problem has been checked. Next, fuzzy logic is employed to control the plate response. Figure 13 shows voltages applied on actuator when plate is controlled by SMC with boundary layer. Note that now high frequency fluctuations (chattering) is absent. Figure 14 shows controlled response of the plate with fuzzy SMC approach. Figure 15 shows voltages applied on the actuator. Chattering is now absent in the control voltage response. Moreover, control voltage decay is very smooth. A preliminary experiment is also conducted to test the robustness of the sliding mode controller. For this purpose a mass of 20 grams is placed at centre of free edge (opposite to cantilevered edge) of the plate. Figures 16 and 17 show controlled response of the 


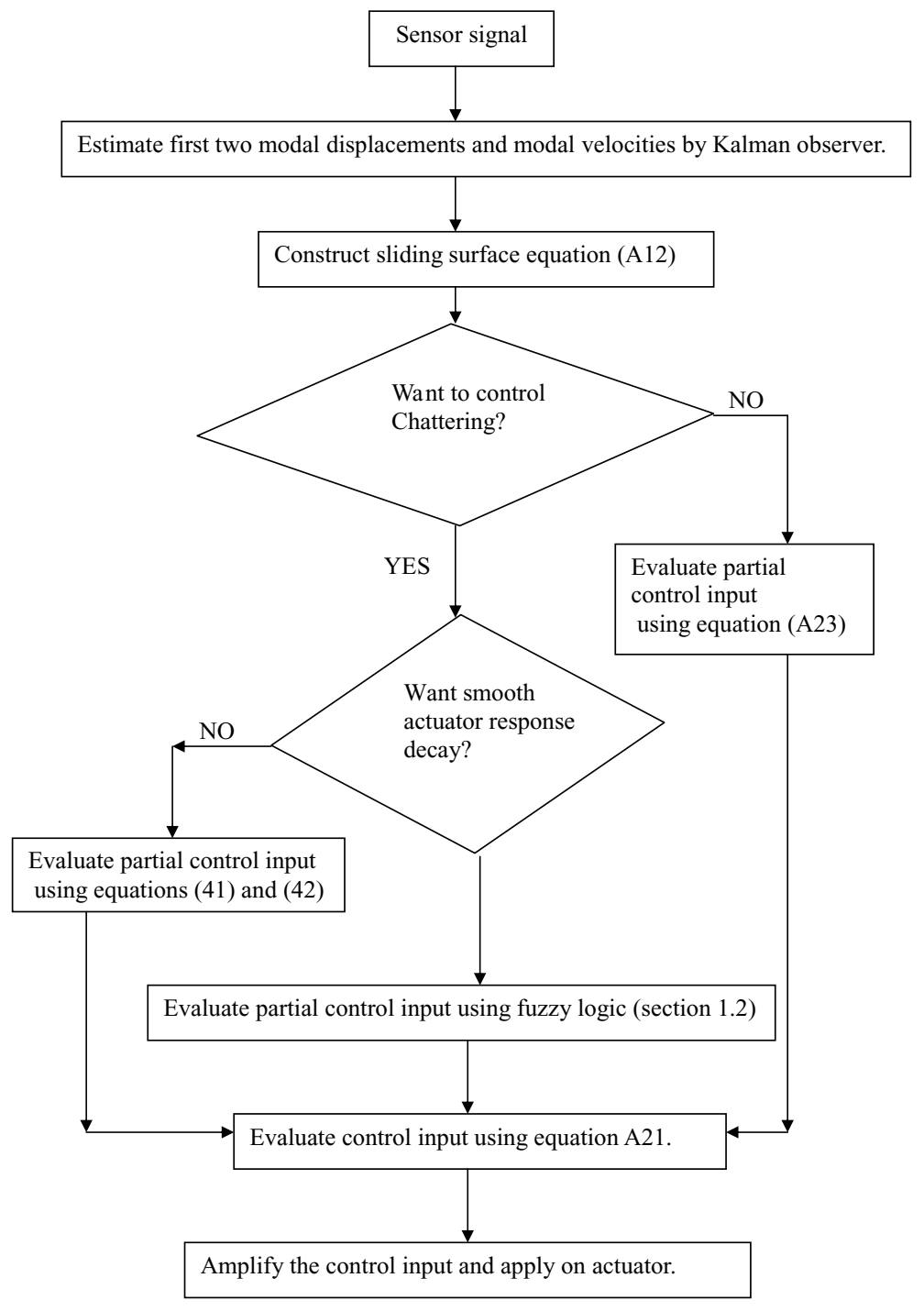

Fig. 4. Block diagram depicting various control schemes.

plate by SMC and fuzzy SMC respectively. There is slight reduction in performance by disturbing the model but still considerable amount of damping enhancement is visible in the controlled response in both the cases. Performance of both the controllers is tabulated in Table 4.

\section{Conclusions}

For systems which suffer from mismatched time varying uncertainties, sliding mode control gives satisfactory performance. In sliding mode control, actuator response fluctuates infinitely fast when sliding mode is reached. This leads to chattering of control input. Introduction of boundary layer in the discontinuous part of the controller, checks chattering. With this modification chattering is controlled, but the decay of control action is very abrupt. This abrupt fall of control input may excite higher modes in practical situations. In this work fuzzy logic is embedded with sliding mode control in order to check chattering problem of SMC. A new fuzzy sliding mode controller is proposed in this paper. Unlike SMC, voltage decay in fuzzy sliding mode control is very smooth. So, fuzzy sliding mode 

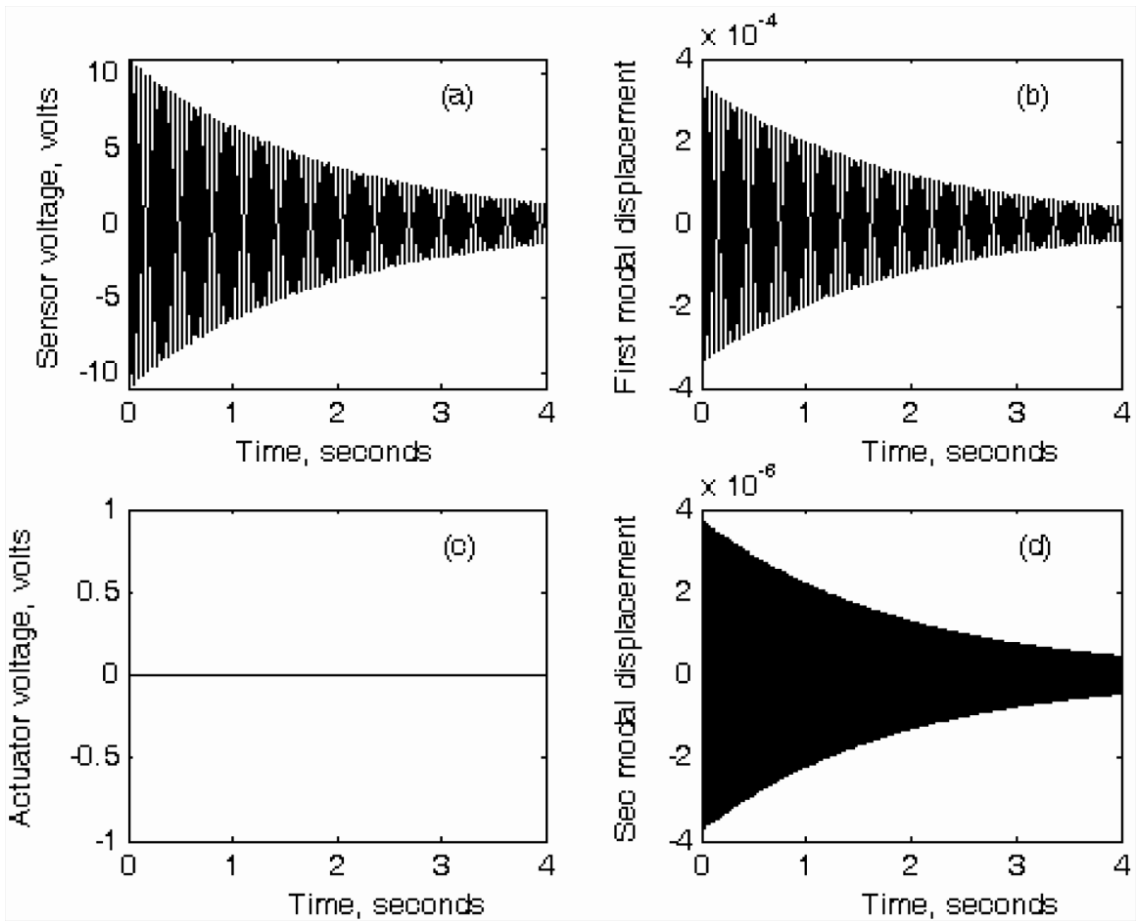

Fig. 5. Uncontrolled response of the (a) sensor voltage, (b) first modal displacement, (c) actuator voltage and (d) second modal displacement.
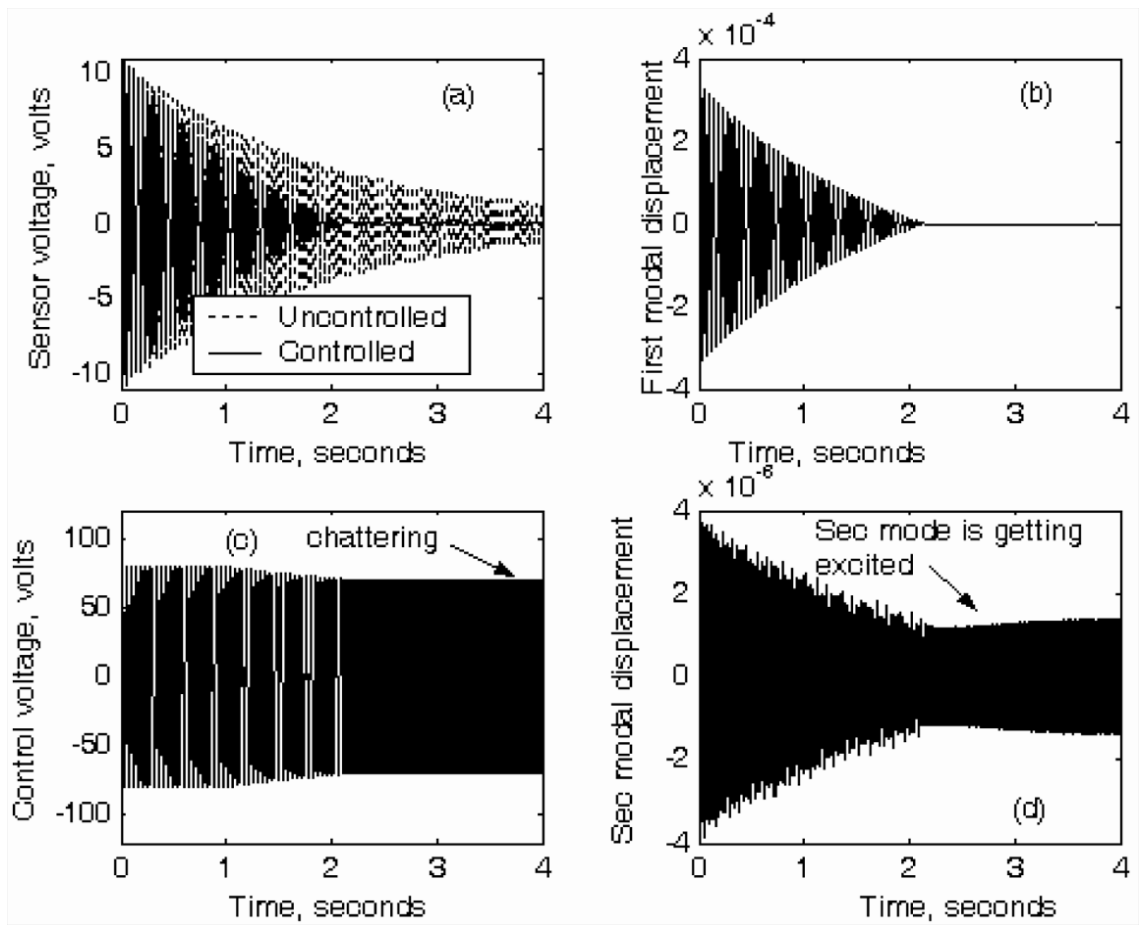

Fig. 6. SMC without boundary layer (a) sensor voltage, (b) first modal displacement, (c) actuator voltage and (d) second modal displacement. 

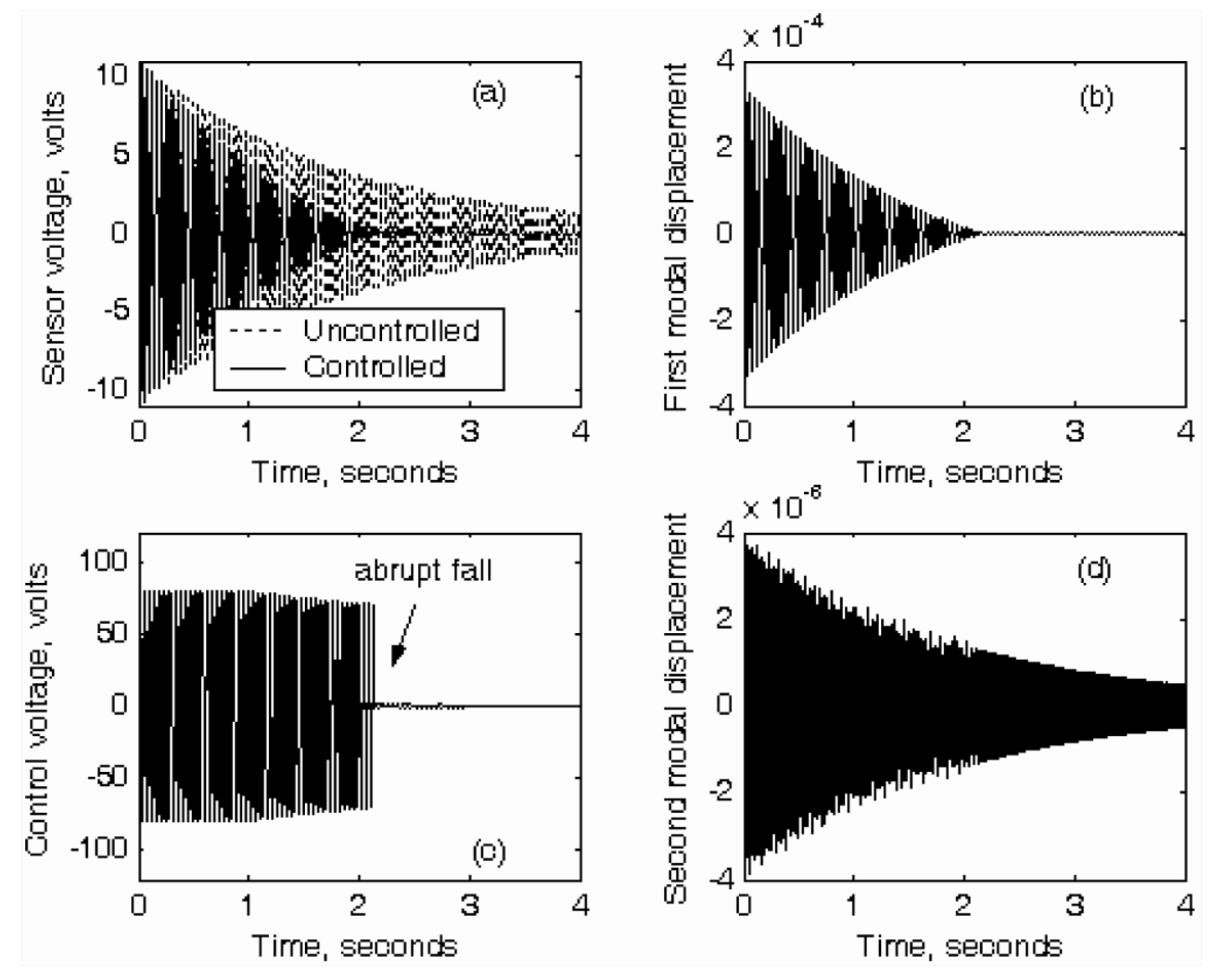

Fig. 7. SMC with boundary layer (a) sensor voltage, (b) first modal displacement, (c) actuator voltage and (d) second modal displacement.
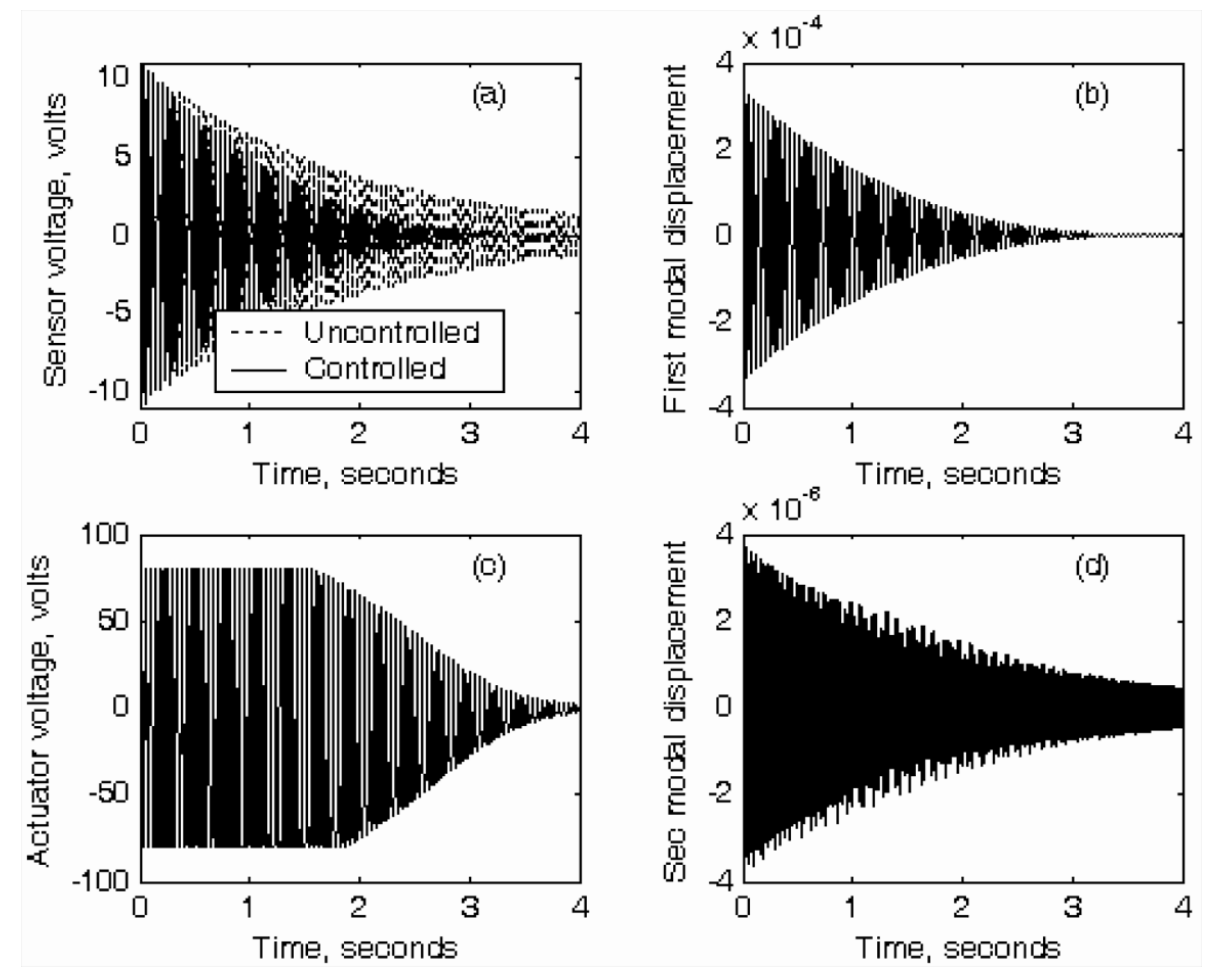

Fig. 8. SMC with fuzzy logic (a) sensor voltage, (b) first modal displacement, (c) actuator voltage and (d) second modal displacement. 


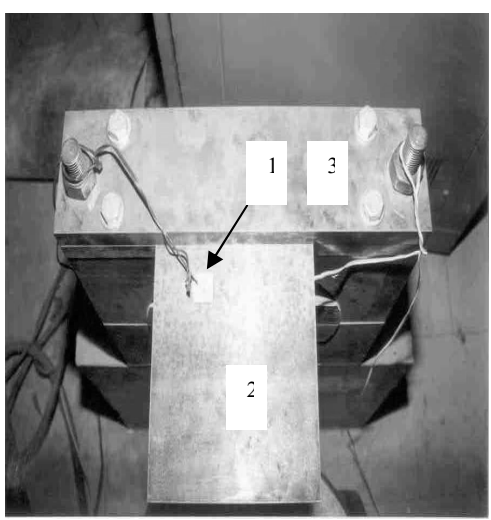

(a)

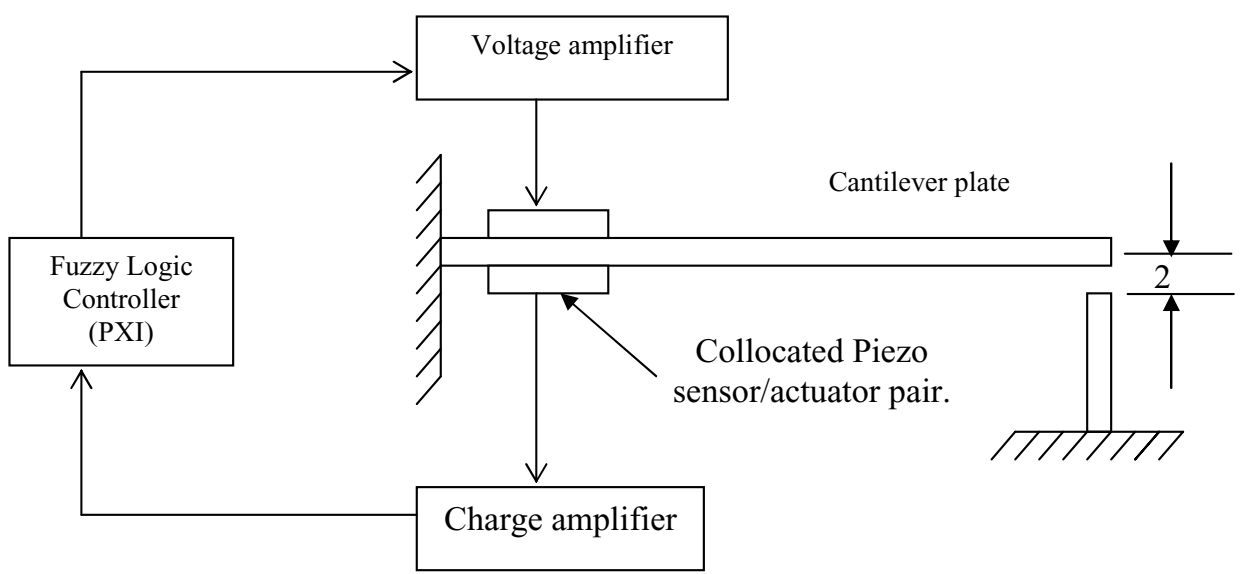

(b)

Fig. 9. (a) Smart plate with single actuator scheme, 1. piezoelectric patch, 2. cantilevered plate and 3. mechanical clamp. (b) Schematic diagram of the experimental set up.

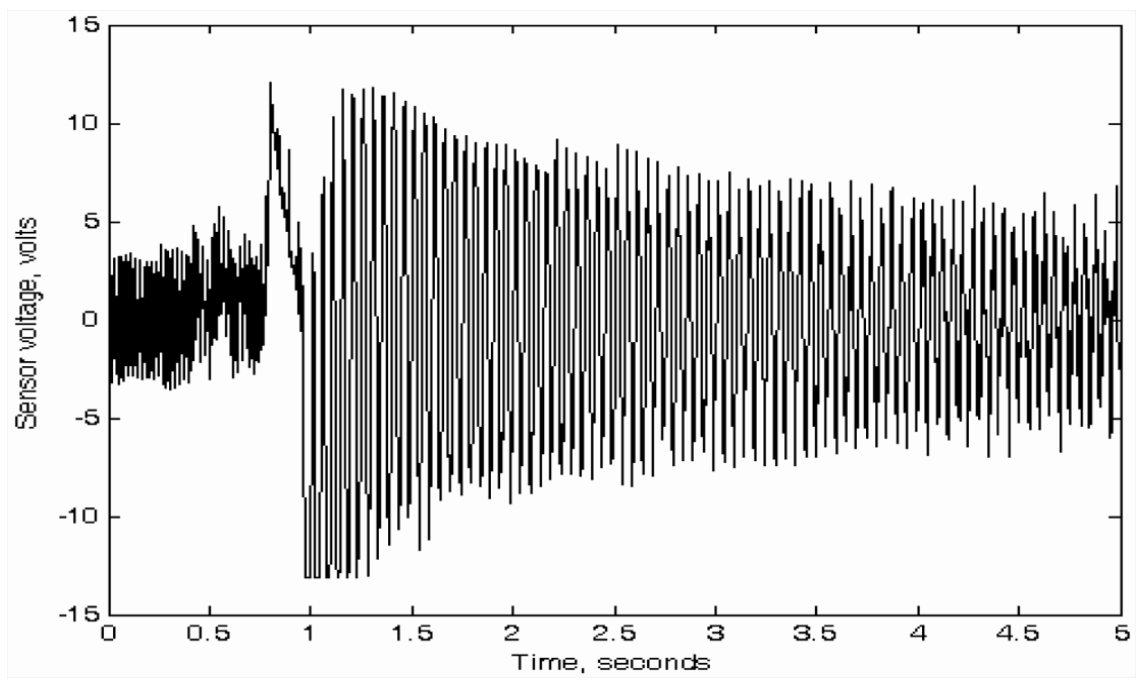

Fig. 10. SMC of plate without boundary layer. 


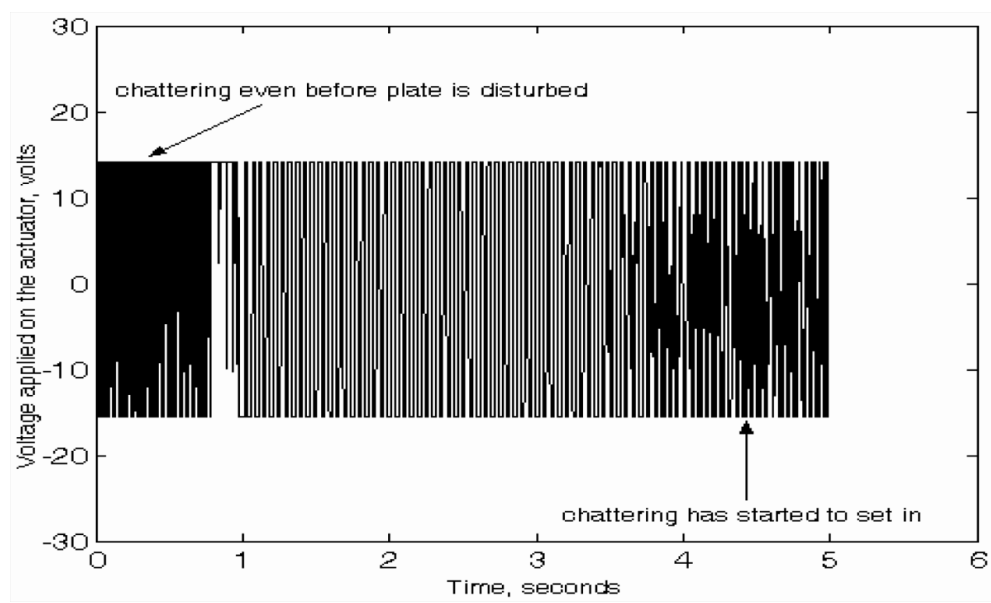

Fig. 11. Voltages applied on actuator when plate is controlled by SMC without boundary layer.

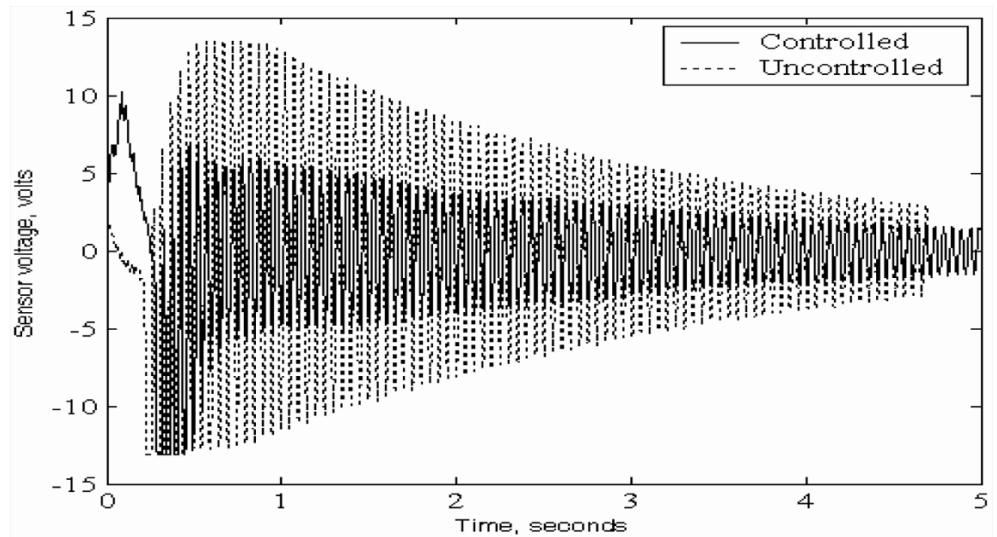

Fig. 12. SMC of plate with boundary layer.

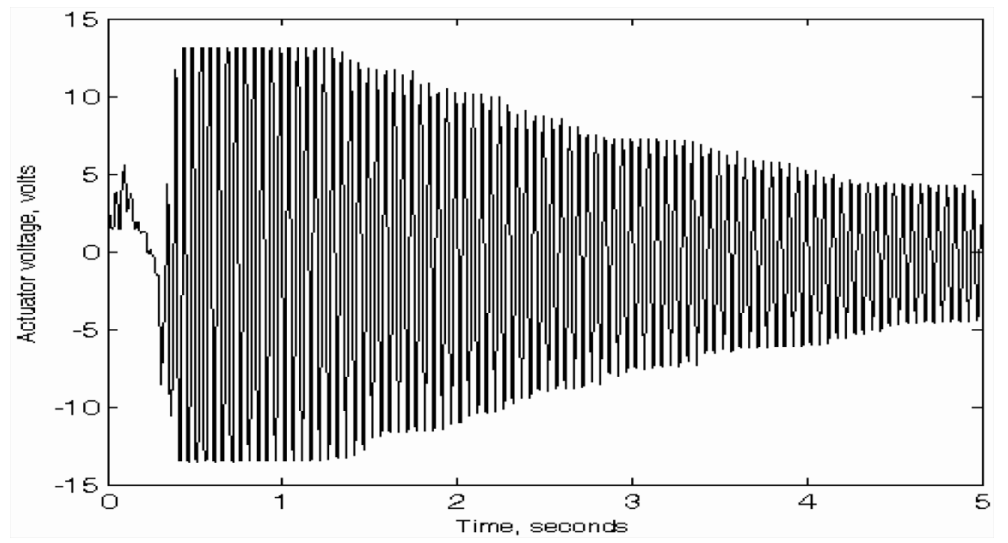

Fig. 13. Voltages applied on actuator when plate is controlled by SMC with boundary layer. 


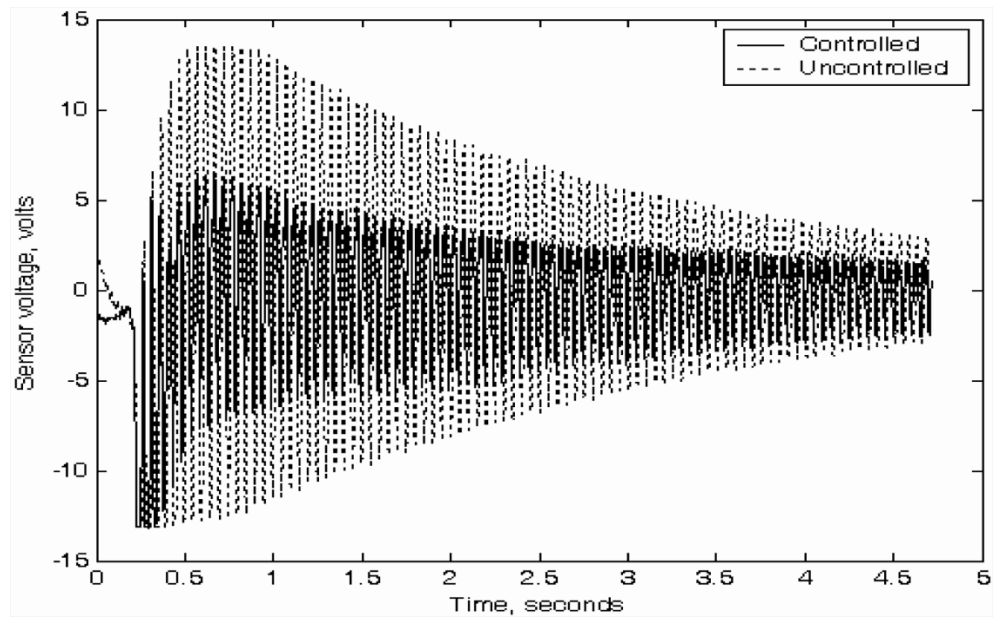

Fig. 14. Fuzzy logic based SMC of plate.

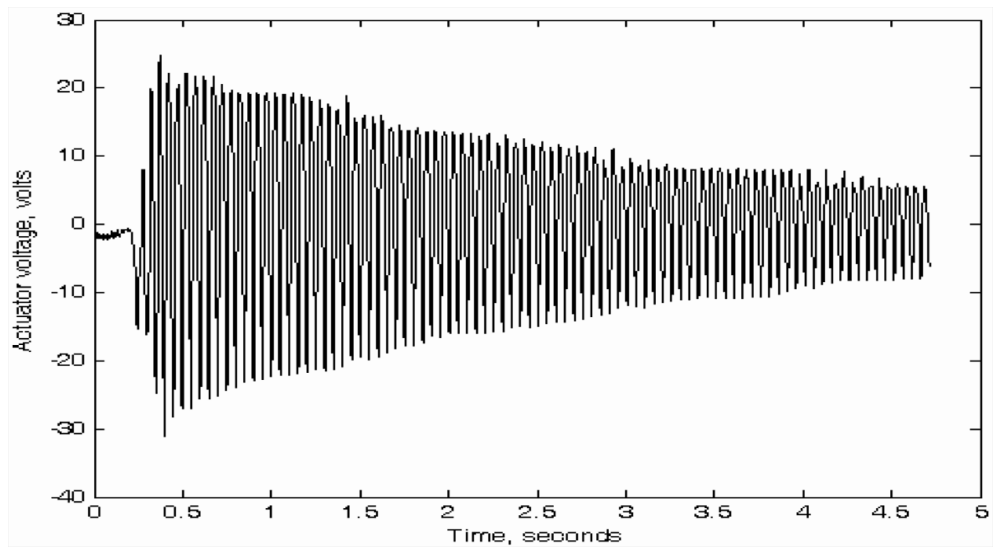

Fig. 15. Voltages applied on actuator when plate is controlled by fuzzy SMC.

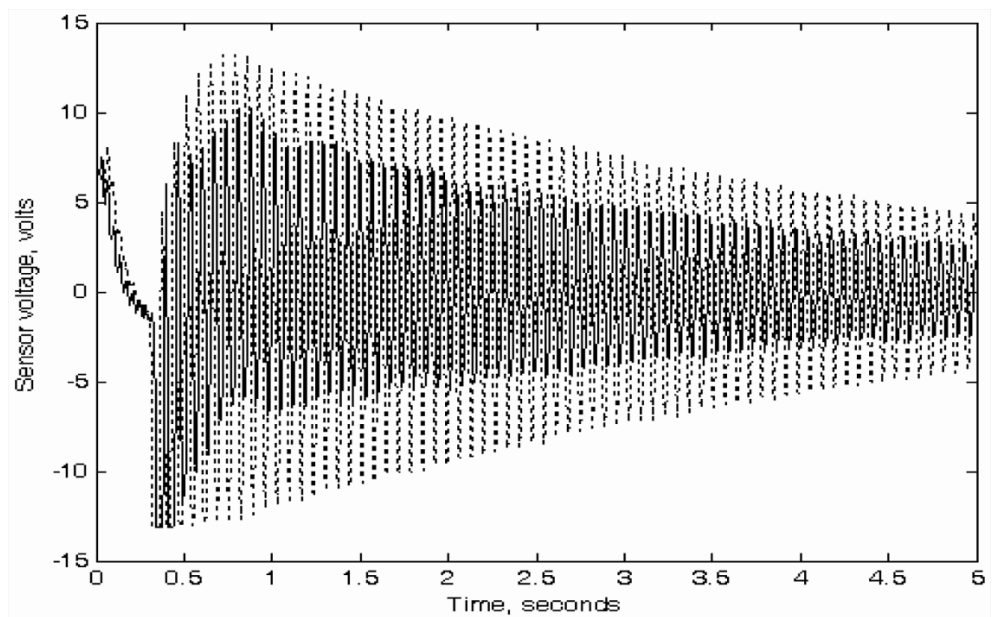

Fig. 16. Response of the plate when tip mass of 20 grams is placed on free edge and is controlled by SMC (with boundary layer). 
Table 4

Comparison of performance of SMC with boundary layer with fuzzy SMC

\begin{tabular}{clll}
\hline S.No & & Sliding mode control with boundary layer & Fuzzy sliding mode control \\
\hline 1 & Chattering problem & Chattering problem is corrected & Chattering problem is corrected \\
2 & Decay of actuator voltage & Abrupt decay & Smooth decay \\
3 & Performance when mass of $20 \mathrm{gm}$ is & Performs well & Performs well \\
& & \\
\hline
\end{tabular}

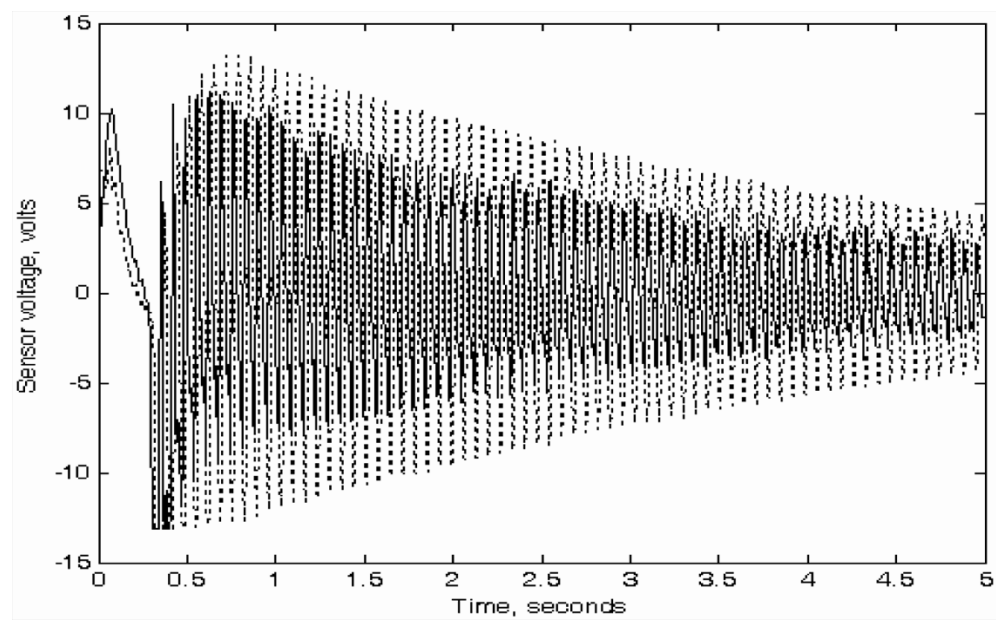

Fig. 17. Response of the plate when tip mass of 20 grams is placed on free edge and is controlled by fuzzy SMC.

control does not excite higher modes of the plate. Robustness of fuzzy sliding mode control is shown by observing control performance when mass of 20 grams is placed at the centre of free edge (edge opposite to the cantilevered edge). SMC with introduction of boundary layer in discontinuous part, is also shown to perform well when mass of 20 grams is placed at the centre of free edge.

\section{Appendix}

The system model

Let the finite element model of the plate be expressed in state space form as under:

$$
\begin{aligned}
& \dot{s}=A s+B u \\
& y=c s
\end{aligned}
$$

Where $s \in R^{n}$ is the state vector defined as

$$
s=\left\{\begin{array}{l}
\eta_{1} \\
\eta_{2} \\
\cdot \\
\cdot \\
\eta_{n} \\
\dot{\eta}_{1} \\
\dot{\eta}_{2} \\
\cdot \\
\dot{\eta_{n}}
\end{array}\right\}
$$


$\eta_{i}$ is $i^{\text {th }}$ modal displacement, $A$ and $B$ are known system matrices with proper dimensions, $u \in R^{m}$ is the control input vector and $y \in R^{l}$ is the output vector. If $\Delta A$ is uncertainty in matrix $A$ then state space equation of the plate becomes

$$
\dot{s}=(A+\Delta A) s+B u
$$

Equation (A4) is transformed into regular form as under

$$
z(t)=T \times s(t)
$$

Where the state transformation matrix $T$ is assumed to be non-singular and

$$
T B=\left[\begin{array}{l}
0 \\
B_{2}
\end{array}\right], B_{2} \in R^{m \times m}
$$

So, in regular form the state equations take the form

$$
\begin{aligned}
& \dot{z}(t)=\left[\begin{array}{c}
\dot{z}_{1}(t) \\
\dot{z}_{2}(t)
\end{array}\right]=T \dot{s}(t)=T(A+\Delta A(t)) s(t)+T B u(t) \\
& =T(A+\Delta A(t)) T^{-1} z(t)+T B u(t) \\
& =\left[\begin{array}{ll}
A_{11} & A_{12} \\
A_{21} & A_{22}
\end{array}\right]\left[\begin{array}{l}
z_{1}(t) \\
z_{2}(t)
\end{array}\right]+\left[\begin{array}{l}
\Delta A_{1}(t) \\
\Delta A_{2}(t)
\end{array}\right] z(t)+\left[\begin{array}{l}
0 \\
B_{2}
\end{array}\right] u(t)
\end{aligned}
$$

where,

$$
\begin{aligned}
& T A T^{-1}=\left[\begin{array}{ll}
A_{11} & A_{12} \\
A_{21} & A_{22}
\end{array}\right], T \Delta A(t) T^{-1}=\left[\begin{array}{l}
\Delta A_{1}(t) \\
\Delta A_{2}(t)
\end{array}\right] \\
& \Delta A_{1}(t) \in R^{(n-m) \times n}, \Delta A_{2}(t) \in R^{m \times n}
\end{aligned}
$$

$\Delta A_{2}(t)$ satisfies the conventional match condition, as under

$$
\Delta A_{2}(t)=B_{2} \zeta(t)
$$

It is always possible to find the matrix $\zeta(t)$, such that

$$
\zeta(t)=B_{2}^{-1} \Delta A_{2}(t)
$$

with $B_{2}$ being non-singular with rank $m$.

Mismatched time-varying uncertainty, $\Delta A_{1}(t)$ can be assumed to have the form [5]

$$
\Delta A_{1}(t)=D F(t) E
$$

where $D, E$ are constant matrices and $F(t) \in R^{r_{1} \times r_{2}}$ is the uncertain matrix such that following inequality holds good

$$
F^{T}(t) F(t) \leqslant I
$$

$I$ is the identity matrix.

\section{Definition of the sliding surface}

Sliding surface is defined as

$$
S=C z(t)=C_{1} z_{1}+C_{2} z_{2}=0
$$

where,

$$
C=\left[\begin{array}{ll}
C_{1} & C_{2}
\end{array}\right], C_{1} \in R^{m \times(n-m)}, C_{2} \in R^{m \times m}
$$

The motion of the sliding mode is asymptotically stable, if the following condition holds:

$$
S^{T} \times \dot{S} \leqslant 0, \forall t \geqslant 0
$$




\section{Definition of the control law}

Control law in SMC is established so as to satisfy inequality (A14). Let us evaluate left hand side of inequality (A14).

$$
S^{T} \dot{S}=S^{T} C \dot{z}(t)=S^{T}\left(C_{1} \dot{z}_{1}+C_{2} \dot{z}_{2}\right)
$$

using Eq. (A7), we have

$$
\begin{aligned}
S^{T} \dot{S}= & S^{T}\left(C_{1}\left(A_{11} z_{1}(t)+A_{12} z_{2}(t)+\Delta A_{1}(t) z(t)\right)+C_{2}\left(A_{21} z_{1}(t)\right.\right. \\
& \left.\left.+A_{22} z_{2}(t)+\Delta A_{2}(t) z(t)+B_{2} u(t)\right)\right)
\end{aligned}
$$

Substituting for $\Delta A_{1}(t)$ from Eq. (A10) and for $\Delta A_{2}(t)$ from Eq. (A8), we have

$$
S^{T} \dot{S}=S^{T}\left(\begin{array}{l}
C_{1}\left(A_{11} z_{1}(t)+A_{12} z_{2}(t)+D F(t) E z(t)\right) \\
+C_{2}\left(A_{21} z_{1}(t)+A_{22} z_{2}(t)+B_{2} \zeta(t) z(t)+B_{2} u(t)\right)
\end{array}\right)
$$

According to Chan et al. [5], if inequality (A11) is satisfied then, for all $x, y \in R^{n}$

$$
2 x^{T} F(t) y \leqslant x^{T} x+y^{T} y,
$$

is also satisfied. Employing inequality (A18) in equation (A17), we have

$$
\begin{aligned}
& S^{T} \dot{S} \leqslant S^{T}\left(C_{1}\left(A_{11} z_{1}(t)+A_{12} z_{2}(t)\right)+C_{2}\left(A_{21} z_{1}(t)+A_{22} z_{2}(t)\right)\right) \\
& \quad+\frac{1}{2}\left(S^{T} C_{1} D D^{T} C_{1}^{T} S+z(t)^{T} E^{T} E z(t)\right)+S^{T} C_{2} B_{2} \zeta(t) z(t)+S^{T} C_{2} B_{2} u(t)
\end{aligned}
$$

If following sliding coefficient matching condition is satisfied

$$
\operatorname{rank}\left[C^{T}\right]=\operatorname{rank}\left[C^{T} \mid E^{T}\right]
$$

then Chan et al. [5] have derived that the control input can be expressed as

$$
\begin{aligned}
u(t)= & u_{m}(t)-\left(C_{2} B_{2}\right)^{-1}\left(C_{1}\left(A_{11} z_{1}(t)+A_{12} z_{2}(t)\right)+C_{2}\left(A_{21} z_{1}(t)+A_{22} z_{2}(t)\right)\right) \\
& -\frac{1}{2}\left(C_{2} B_{2}\right)^{-1}\left(C_{1} D D^{T} C_{1}^{T} S+E_{a}^{T} E_{a} S\right)-\left(C_{2} B_{2}\right)^{-1}\left(k_{1} \operatorname{sgn}(S)+k_{2} S\right)
\end{aligned}
$$

with $E=E_{a} C, E_{a} \in R^{r_{2} \times m}, k_{1}>0, k_{2}>0, k_{1} \in R, k_{2} \in R$.

Substituting, Eq. (A21) in Eq. (A19), we have

$$
S^{T} \dot{S} \leqslant S^{T}\left(C_{2} B_{2} \zeta(t) z(t)-C_{2} B_{2} u_{m}(t)-k_{1} \operatorname{sgn}(S)-k_{2} S\right)
$$

Now, $u_{m}(t)$ is defined further as:

$$
u_{m}(t)= \begin{cases}-\frac{B_{2}^{T} C_{2}^{T} S}{\left\|B_{2}^{T} C_{2}^{T} S\right\|} \rho & \text { if } S \neq 0 \\ 0 & \text { if } S=0\end{cases}
$$

Also since, $\Delta A_{2}(t)$ satisfies the conventional match condition, we can assume

$$
\|\zeta(t) z(t)\| \leqslant \rho
$$

Using Eqs (A23) and (A24) we observe that

$$
S^{T} C_{2} B_{2} \zeta(t) z(t)+S^{T} C_{2} B_{2} u_{m}(t)<0, \forall S \neq 0
$$

Thus, with $k_{1}, k_{2}>0$, inequality (A24) and inequality (A25) it is easy to find that

$$
S^{T} \dot{S}<0, \forall S \neq 0
$$

That is, the sliding mode is guaranteed. The result is summarized below in Theorem 1.

Theorem 1. Consider a linear uncertain system in the regular form

$$
\dot{z}(t)=\left[\begin{array}{l}
\dot{z}_{1}(t) \\
\dot{z}_{2}(t)
\end{array}\right]=\left[\begin{array}{l}
A_{11} A_{12} \\
A_{21} A_{22}
\end{array}\right]\left[\begin{array}{l}
z_{1}(t) \\
z_{2}(t)
\end{array}\right]+\left[\begin{array}{l}
\Delta A_{1}(t) \\
\Delta A_{2}(t)
\end{array}\right] z(t)+\left[\begin{array}{l}
0 \\
B_{2}
\end{array}\right] u(t)
$$

with time varying uncertainty

$$
\Delta A_{1}(t)=D F(t) E \text { and } F^{T}(t) F(t) \leqslant I .
$$

If there exists a sliding coefficient matrix $C$ such that the sliding coefficient matching condition is satisfied and $C_{2} B_{2}$ is invertible, then the sliding mode for the variable structure control of the linear uncertain system is guaranteed. 


\section{Design of the sliding coefficient matrix $C$}

The sliding coefficient matrix for the linear system in Eq. (A27) with the time-varying uncertainty

$$
\Delta A_{1}(t)=D F(t) E \text { and } F^{T}(t) F(t) \leqslant 1,
$$

is designed to satisfy the sliding coefficient matching condition,

$$
\operatorname{rank}\left[C^{T}\right]=\operatorname{rank}\left[C^{T} \mid E^{T}\right]
$$

Chan et al. [5] has shown that if

1. Sliding coefficient matching condition is satisfied

2. $C_{2} B_{2}$ is invertible and

3. $A_{11}-A_{12} C_{2}^{-1} C_{1}$ has all the eigen values negative

then linear system with mismatched time-varying uncertainties given in Eq. (A27) is guaranteed to reach the sliding mode with the variable structure control presented in Eq. (A21) and the variable structure control system is asymptotically stable on the sliding surface.

\section{References}

[1] Y.S. Amant and L. Cheng, Simulations and Experiments on Active Vibration Control of a Plate with Integrated Piezoceramics, Thin Walled Structures 38 (2000), 105-123.

[2] M.R. Bai and G.M. Lin, The Development of a DSP-Based Active Small Amplitude Vibration Control System for Flexible Beams by using the LQG Algorithms and Intelligent Materials, Journal of Sound and Vibration 198(4) (1996), 411-427.

[3] A. Baz and S. Poh, Performance of an Active Control System with Piezoelectric Actuators, Journal of Sound and Vibration 126(2) (1988), $327-343$.

[4] A. Blanguernon, F. Lene and M. Bernadou, Active Control of a Beam Using a Piezoceramic Element, Smart Materials and Structures $\mathbf{8}$ (1999), 116-124.

[5] M. Chan, C.W. Tao and T. Lee, Sliding mode controller for linear systems with mismatched time-varying uncertainties, Journal of the Franklin Institute 337 (2000), 105-115.

[6] S.B. Choi and J.S. Kim, A Fuzzy-Sliding Mode Controller for Robust Tracking of Robotic Manipulators, Mechatronics 7(2) (1997), 199-216.

[7] S.B. Choi and M.S. Kim, New Discrete-Time, Fuzzy-Sliding-Mode Control with Application to Smart Structures, Journal of Guidance, Control, and Dynamics 20(5) (1997), 857-864.

[8] C.R. Fuller, S.J. Elliott and P.A. Nelson, Active Control of Vibration, Academic Press, Harcourt Brace \& Company, 1996.

[9] IEEE Standard on Piezoelectricity, American National Standards Institute, 1988.

[10] D.J. Inman, Vibration, with Control, Measurement and Stability, Prentice Hall, Englewood Cliffs, New Jersey, 1989.

[11] M.K. Kwak and D. Sciulli, Fuzzy-Logic Based Vibration Suppression Control Experiments on Active Structures, Journal of Sound and Vibration 191 (1996), 15-28.

[12] Y.Y. Li and L.H. Yam, Robust Vibration Control of Uncertain Systems using Variable Parameter Feedback and Model-based Fuzzy Strategies, Computers and Structures 79 (2001), 1109-1119.

[13] K. Ma, Adaptive Non-linear Control of a Clamped Rectangular Plate with PZT Patches, Journal of Sound and Vibration 264 (2003), $835-850$.

[14] W.J. Manning, A.R. Plummer and M.C. Levesley, Vibration Control of a Flexible Beam with Integrated Actuators and Sensors, Smart Materials and Structures 9 (2000), 932-939.

[15] L. Meirovitch, Dynamics and Control of Structures, John Wiley \& sons, 1989.

[16] A. Preumont, Vibration Control of Active Structures, Kluwer Academic Publishers, Netherlands, 2002.

[17] S.P. Singh, H.S. Pruthi and V.P. Agarwal, Efficient Modal Control Strategies for Active Control of Vibrations, Journal of Sound and Vibration 262 (2003), 563-575.

[18] C.S. Ting, T.H.S. Li and F.C. Kung, Design of fuzzy controller for active suspension system, Mechatronics 5(4) (1995), 365-383.

[19] O. Tokhi and S. Veres, Active Sound and Vibration Control, The Institution of Electrical Engineers, London, United Kingdom, 2002.

[20] A. Tsoukkas and H. Vanlandingham, Application of Fuzzy-Logic Control to Active Vibration Damping, Proceedings of the Eighth VPI\&SU Symposium on Dynamics and Control of Large Structures, 1991, 371-379.

[21] S.M. Yang and Y.J. Lee, Vibration Suppression with Optimal Sensor/Actuator Location and Feedback Gain, Smart Materials and Structures 2 (1993), 232-239. 

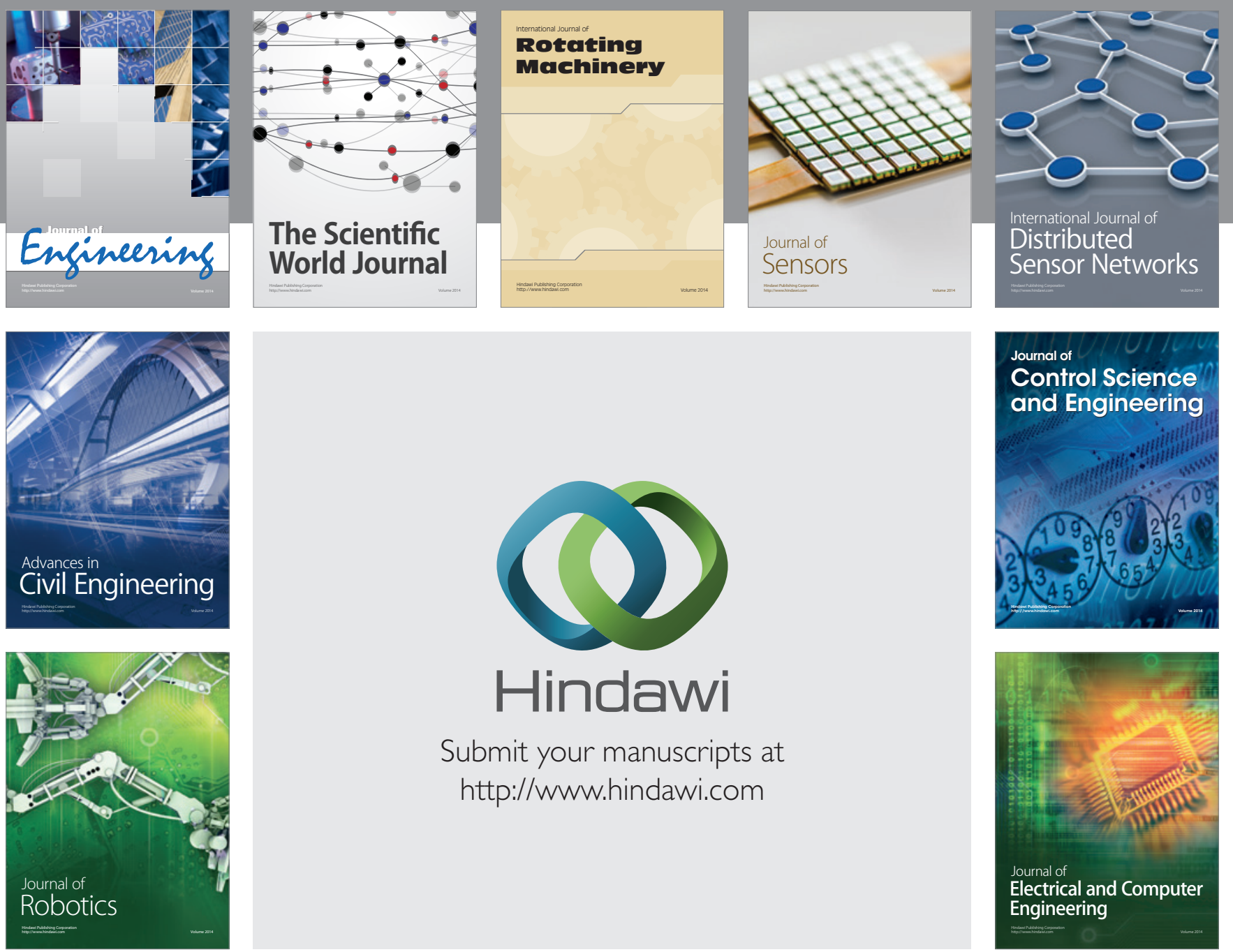

Submit your manuscripts at

http://www.hindawi.com
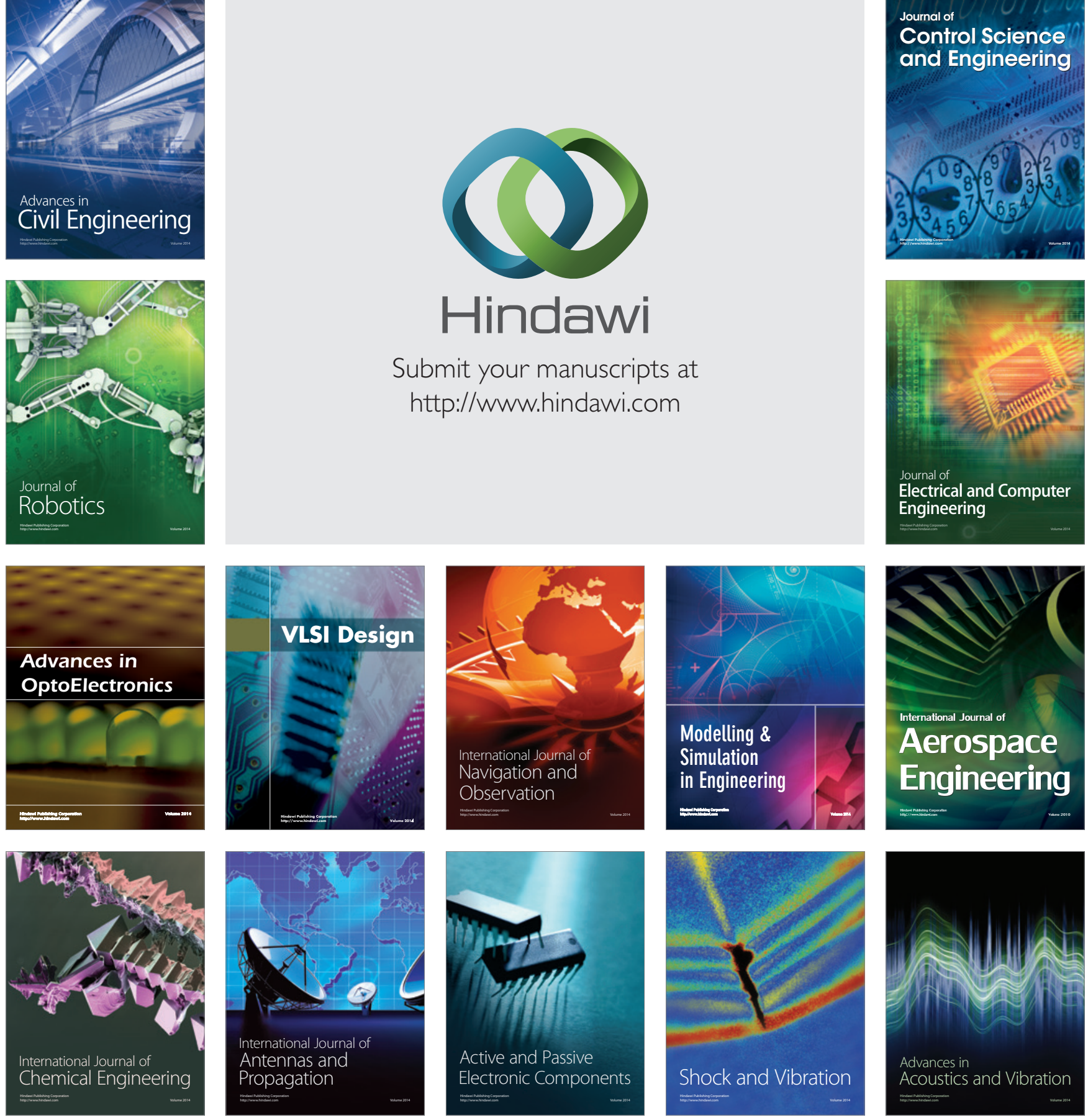